المجلد 02 / العدد: 04 (2020)، ص ص 21 -61

المجلة العلمية للعلوم التربوية والصحة النفسية

ISSN: 2682-2865

The Online ISSN : 2682-4248

عشوائية استخدام الدواء في مصرودور التربية الدوائية في مواجهتها

The randomness of drug use in Egypt and the role of drug education in confronting it

$$
\text { جمال على الدهشان' }
$$

'أستاذ أصول التربية والعميد الأسبق لكلية التربية جامعة المنوفية التهان

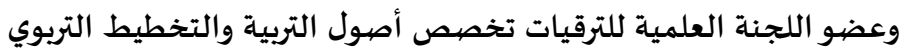

\title{
Mail: g_eldahshan@hotmail.com
}

تاريخ القبول: 2020/09/12

تاريخ الاستلام: 2020/08/10

انطلاقا من انتشار ظاهرة الاستخدام العشوائي للدواء في مصر - وصلت الى

حد وصفها بالفوضى - بصورة أصبحت تسبب مخاطر عديدة منها ما هو طبي وصيحي ومنها ما هو اقتصادي، تلك الظاهرة التي تعددت اسبابها الا ان السبب الرئيس قلة وعى الكثيرين بالأمور الخاصة بالاستخدام الرشيد للدواء، وانطلاقا من دور التربية في رفع مستوى الوعي الصبي، فمن خلالها يزود الطلاب وافراد المجتمع بالمعلومات والخبرات بقصد التأثير في معرفتهم وسلوكهم وميولهم الصحية وكذلك صحتهم وصحة مجتمعهم الذي يعيشون فيه كي ينعموا بحيـاة سليماة.تناقش الورقة الحالية تلك الظاهرة ومخاطرها والدور الذي يمكن ان تلعبه التربية الدوائية في مواجهتها من

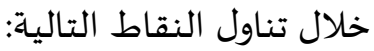

استعراض المقصود بعشوائية استخدام الدواء وأبرز مظاهر تلك العشوائية؟ استعرض اسباب انتشار عشوائية وفوضى استخدام الدواء في المجتمع المصري والمخاطر التي يمكن ان تترتب على انتشارها، ومداخل مواجهتها. 


$$
\begin{aligned}
& \text { استعراض المقصود بالتربية الدوائية وأهدافها والياتها في التغلب على العشوائية في } \\
& \text { استخدام الدواء. } \\
& \text { - التوصيات والمقترحات لتفعيل دور التربية الدوائية في مواجهة الاستخدام } \\
& \text { العشـوائي للدواء في مصر. } \\
& \text { الكلمات المفتاحية: الدواء؛ التربية الدوائية؛ عشوائية استخدام الدواء }
\end{aligned}
$$

\section{Abstract:}

Based on the spread of the phenomenon of indiscriminate drug use in Egypt - reaching the point of describing it as chaotic - in a way that has become causing many risks, some of which are medical and health, and some of which are economic.

One of the role of education in raising the level of health awareness, through which it provides students and community members with information and experiences with the aim of influencing their knowledge, behavior and health tendencies, as well as their health and the health of their community in which they live so that they can enjoy a healthy life.The present paper discusses this phenomenon, its risks, and the role that pharmaceutical education can play in confronting it by addressing the following points:

- Reviews intended by randomization of drug use and the most prominent manifestations of randomness?

- Examine the causes of the random spread and chaos of drug use in Egyptian society, the dangers that could result from their spread, and the approaches to confronting them.

- A review of what is meant by drug education, its goals and mechanisms, in overcoming randomness in drug use.- Recommendations and proposals for activating the role of drug education in facing the indiscriminate use of drugs in Egypt.

Key words: medicine ; drug education ; random use of medicine. 
مقدمة :

الصحة كنز من كنوز الدنيا اعطاها لنا الله،لكن لا نعرف قيمتها لا لعدان

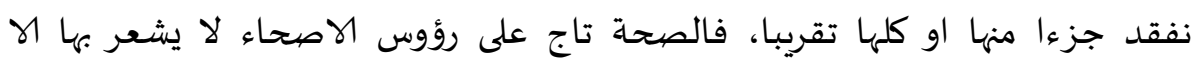

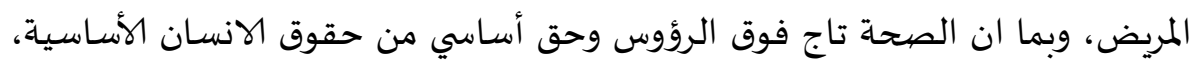

كان لزاما علينا ان نحافظ عليها ونهتم بها.

ونظرا لأهمية صحة الانسان وأثرها على رقى المجتمع وتقدمة، فقد اولت جميع

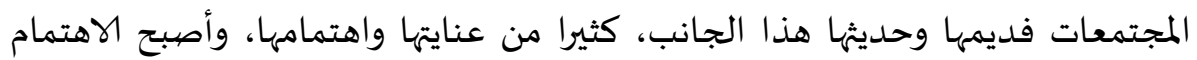

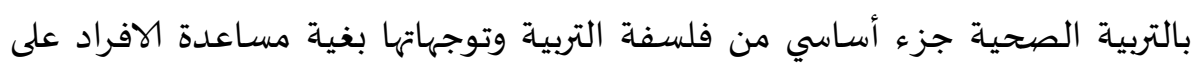

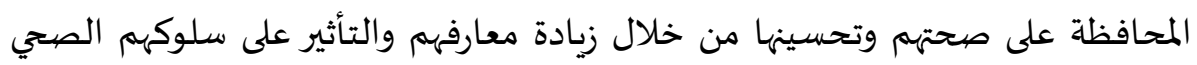
الوقائي والعلاجي.

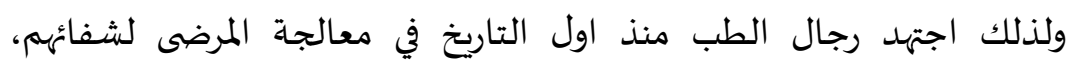

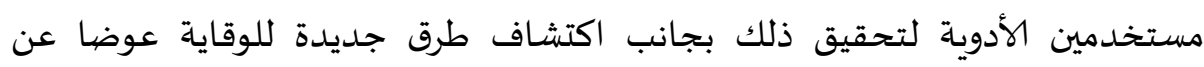

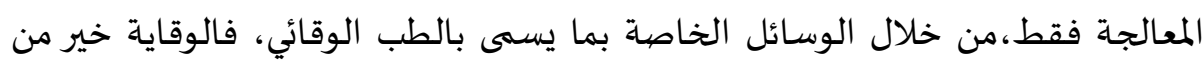

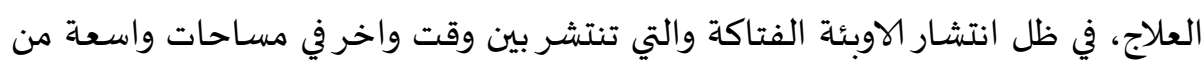

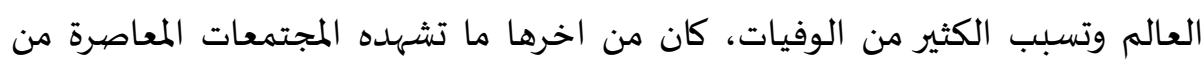

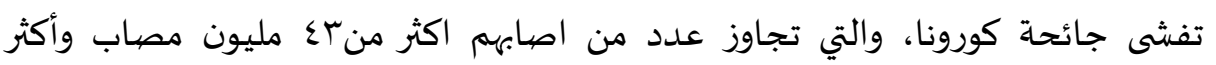

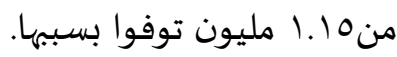

فتناول الأدوية ضرورة تفرضها حالة اضطرارية هي المرض، غير أن تناولها

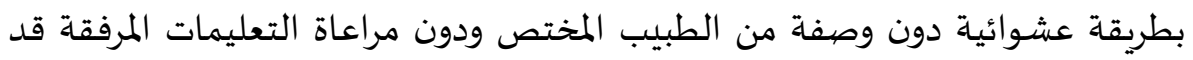
يسبب مضاعفات خطيرة على الصحة ربما أخطر من المرض الذي استدعى تناولها .

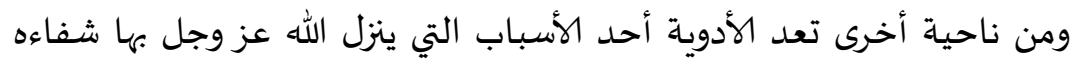

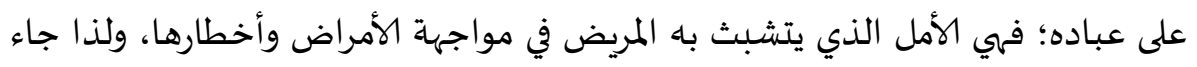

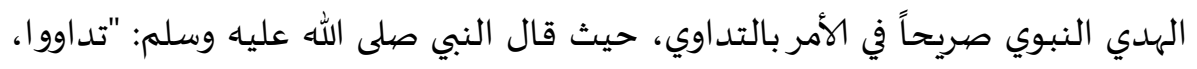

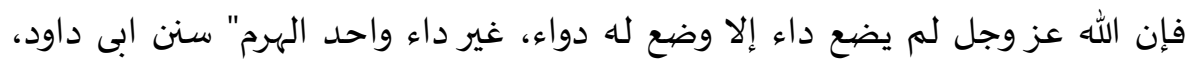


وقال عليه السلام: "ما أنزل الله عزوجل داء، إلا أنزل له دواء؛ علماه من علمه، وجهله من جهله" رواه احمد في مسنده.

فمـع كثيرة الامـراض وانتشـارها كثير استـخدامنا للأدويـة بطريق صسحيحة وغيير

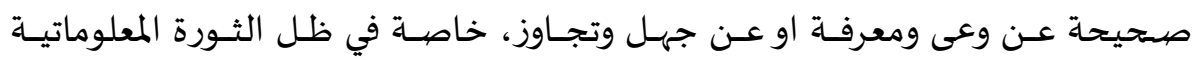

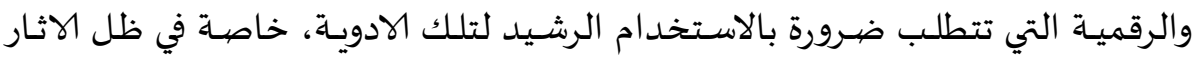

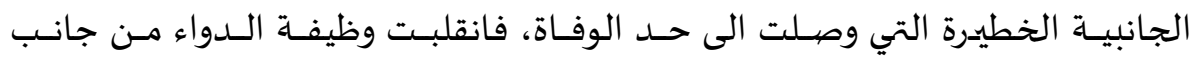

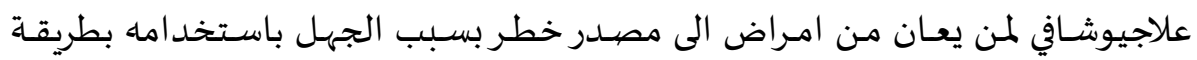

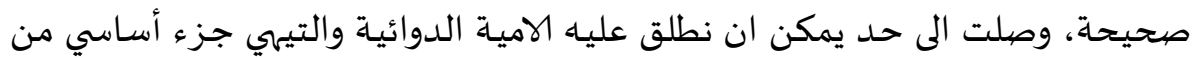

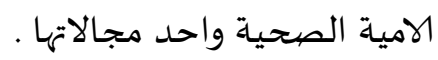

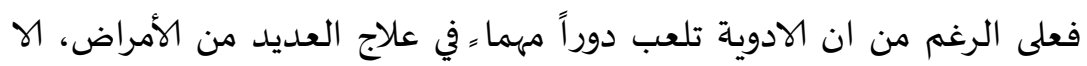

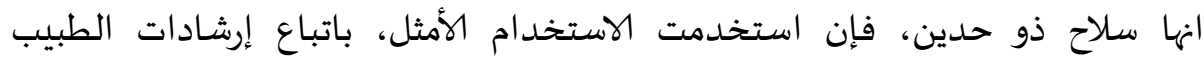

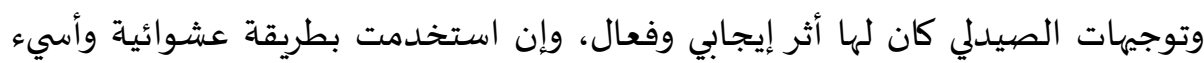

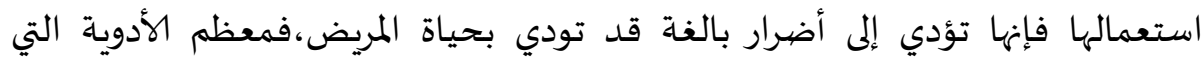

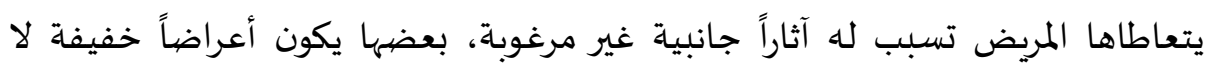
تشكل خطراً على المريض وبعضها قد يهدد حياته.

وفى هذا الإطار اكدت منظمة الصحة العالمية على ان التصدي للضرر المرتبط المبا

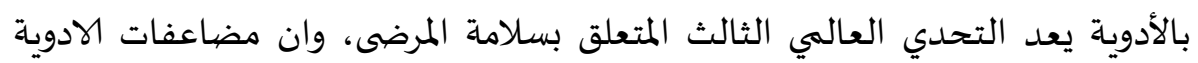

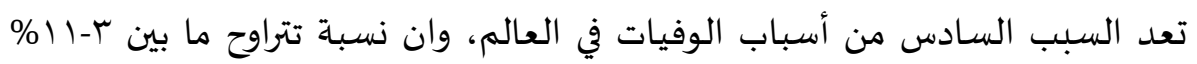
من السكان يعانون من امراض لأسباب دوائية. وانطلاقا من كل ذلك، أصبح لزاما على كافة المؤسسات التربوية ان تقوم بدورها التوعوي والتثقيفي والوقائي بجانب المؤسسات الطبية والصيدلانية، في مجال

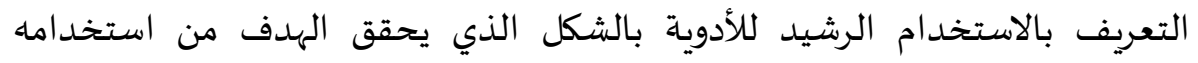

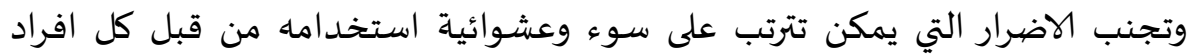
المجتمع المرضى والاصحاء منهم على حد سواء. 
وفى هذا الاطار بدا العديد من الباحثين والكتاب التحدث عن ضرورة محو الامية الصحية خاصة تلك التي تتعلق بالأدوية والعقاقير، في ظل كثرة الاخطاء العديدة المتعلقة بكل جوانب إنتاج الادوية واستخدامها، حيث تشكل الأخطاء الدوائية المشكلة

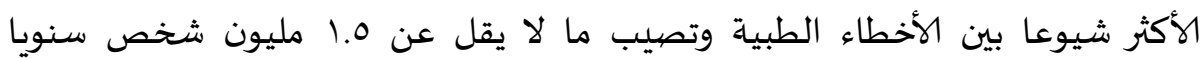

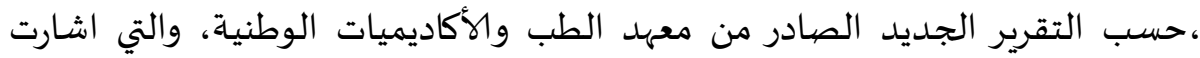

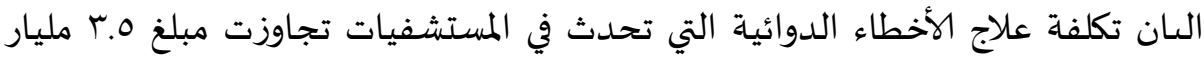

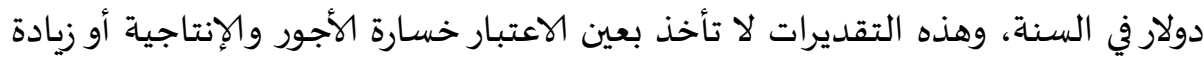

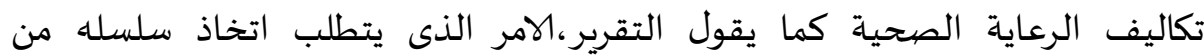

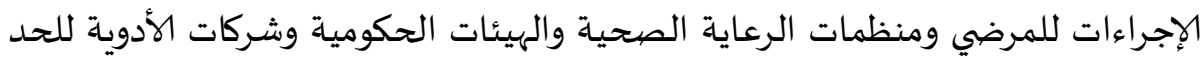

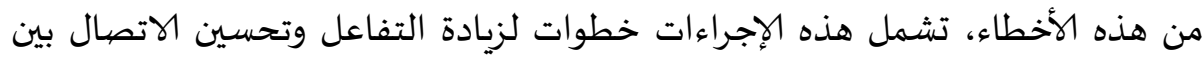

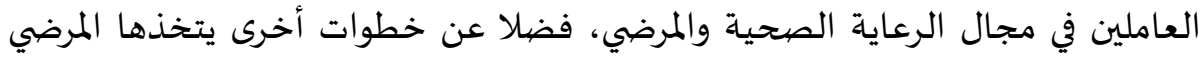

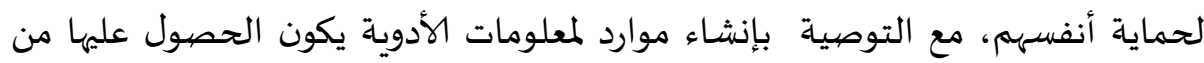

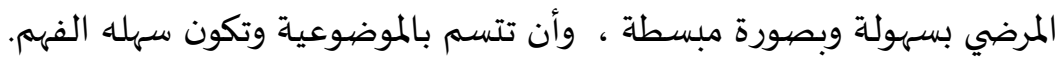
إن تكرار أخطاء استخدام الأدوية والآثار الجانبية التي يمكن منعها يثير قلقا

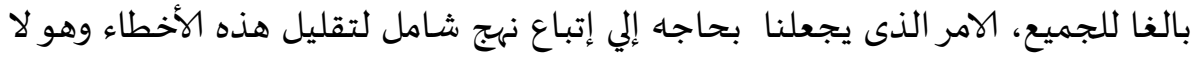

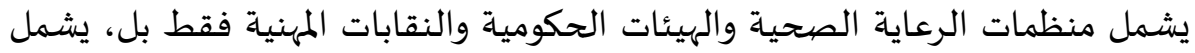

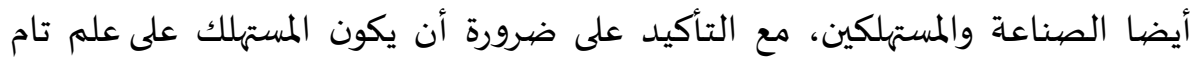

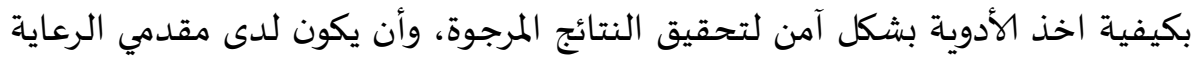

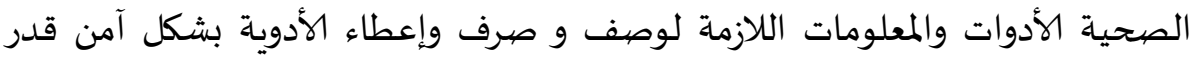

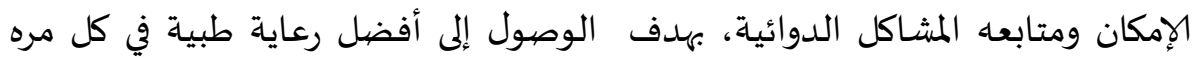

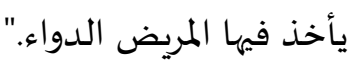

وتتعدد الأخطاء الدوائية وتشمل مجالات من ضمنها الأدوية التي تصرف

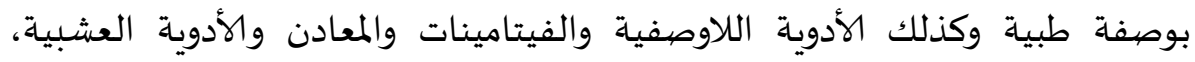

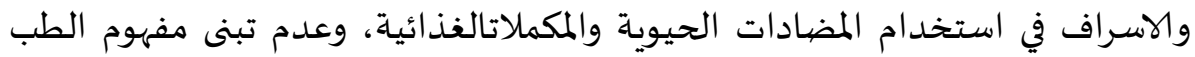


المُسند بالبراهين Evidence-based medicine (أو الطب المعتمد على البرهان) والمعروف أيضا باسم الممارسة القائمة على الأدلة.

إن الأخطاء شائعة في جميع المراحل من وصف الدواء إلى أخذه ومتابعته لرصد

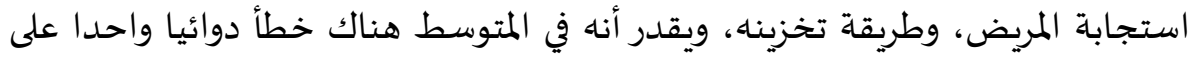

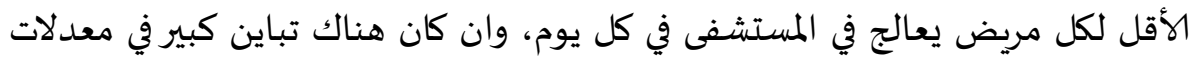

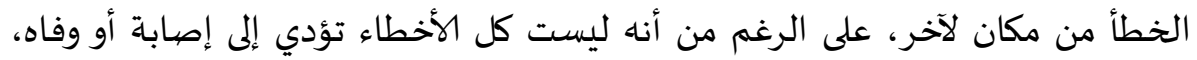

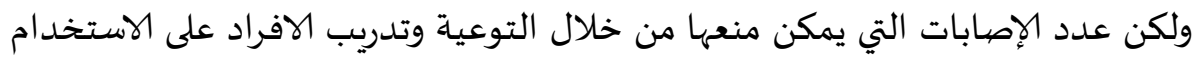
الرشيد لتلك الادوية.

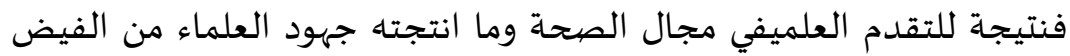
المتدفق لأنواع الادوية والمواد الكيميائية التي تستخدم في الاغراض الطبية كالعلاج

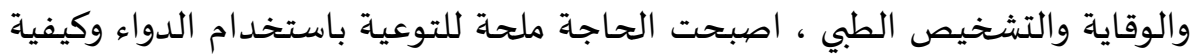

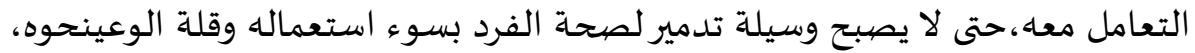
الامر الذي يتطلب ضرورة رفع مستوى إدراك الافراد خاصة الكبار لأبعاد مشكلات الدواء ووقاية المجتمع من اخطاره.

وفى هذا الإطار عقدت الهيئة العامة للغذاء والدواء بالمملكة العربية السعودية

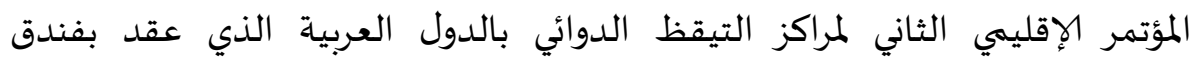

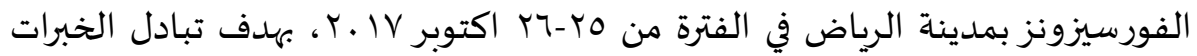
العلمية والتطبيقية والممارسات الإيجابية، حول التوعية باستخدام الدواء بطريقة صحيحة، وتفعيل إمكانيات الهيئة العامة للغذاء والدواء، وجعلها متاحة للمشاركين الإبهاء كافة للاستفادة منها اليوم ومستقبلاًا.

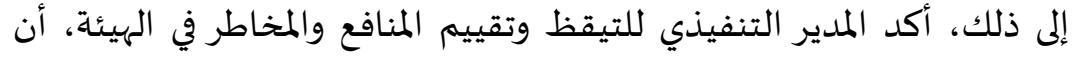

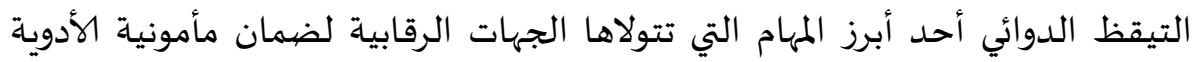

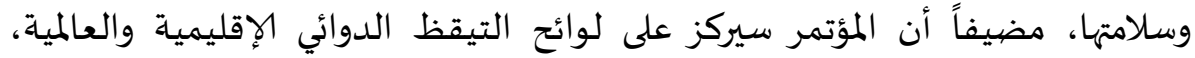

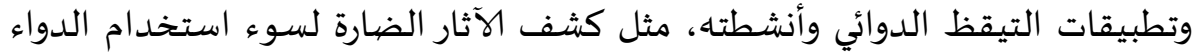


وخطط تقليل المخاطر، ومستجدات جهود مراكز التيقظ الدوائي في المملكة وفي الدول العربية، في تجنب المخاطر، ودور الأبحاث في دعم القرار العلمي لمراكز التيقظ الدودائي. وبحث المؤتمر على اهمية الاستفادة من مخرجات قواعد بيانات التيقظ

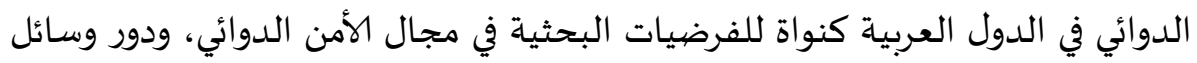

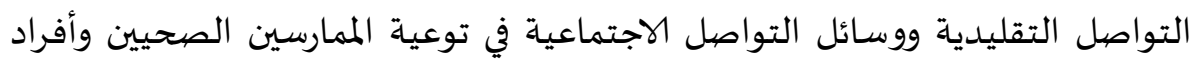

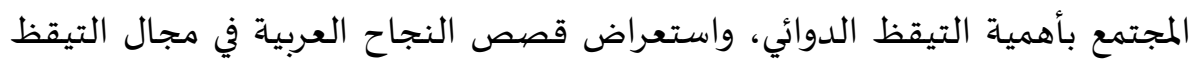

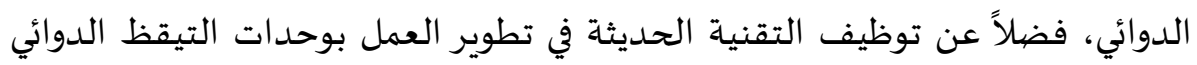

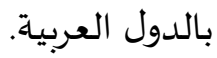

وفى هذا الاطار عقدت كلية الصيدلة بجامعة القصيم والجمعيةالصيدلية

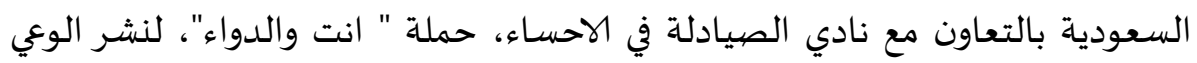

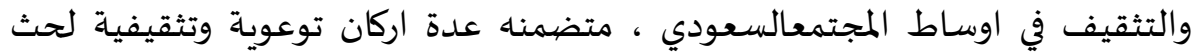

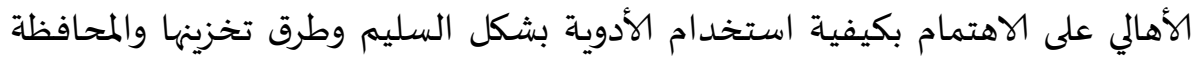

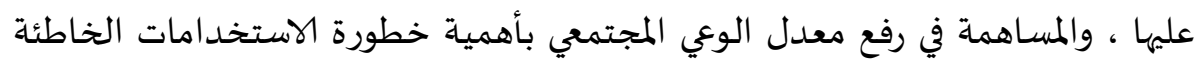

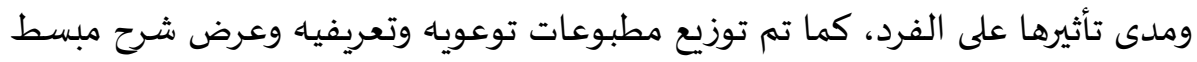

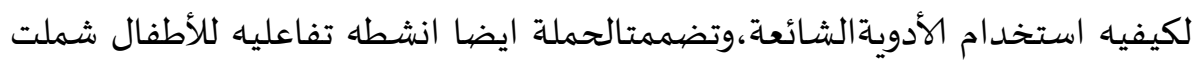
ركن للمرسم الحر والتصوير الفوتوغرافي وركن الصلصال والتراكيب... الطريق الأسلم للحصول على أفضل نتائج علاجية).

كما عقدت كلية الصيدلة بجامعة المستنصرية ندوة علمية نظمها فرع

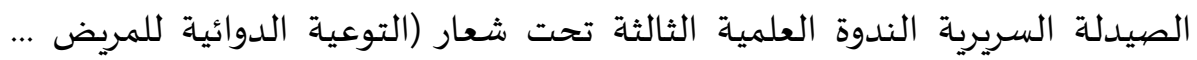

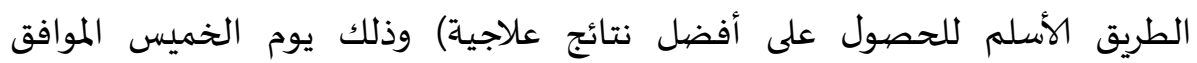

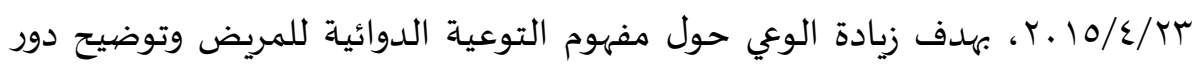

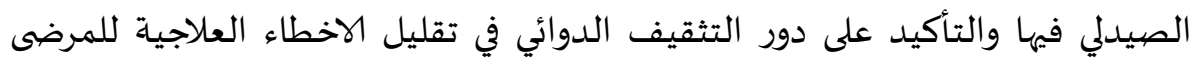


وقدمت مجموعة من التوصيات بهدف محو ما اطلق عليها محو الأمية

الدوائية Pharmaceutical Information LiteracyPatient كان من ابرزها : منوفيا

ا - تعميق مفهوم التوعية الدوائية ووسائل إيصال المعلومة الصحيحة للمريض من

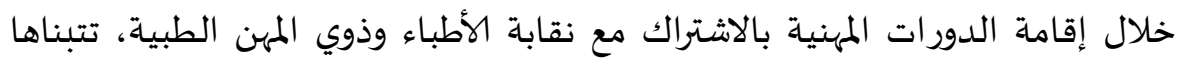

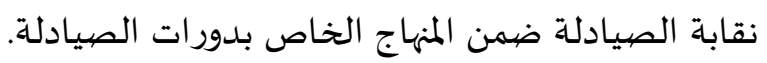

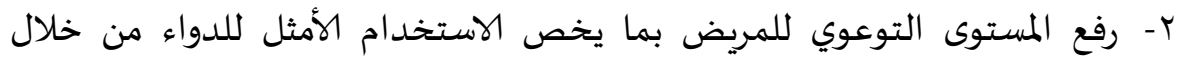

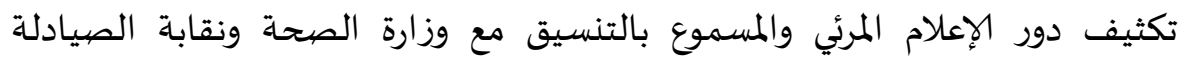
وكذلك إصدار منشورات مبسطة جدا توزع على طلبة المدارس الابتدائية والثانوية

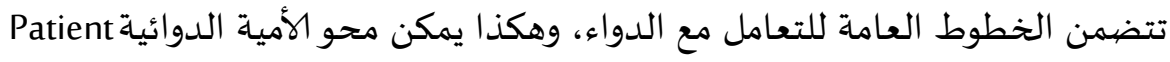

Literacy r- البدء بمشروع Social Pharmacy بالتنسيق بين وزارة الصحة ونقابة الصيادلة من مجتئ

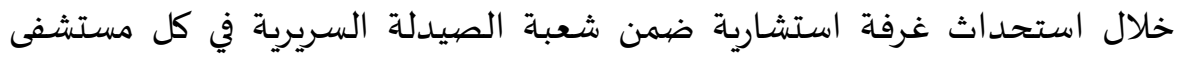

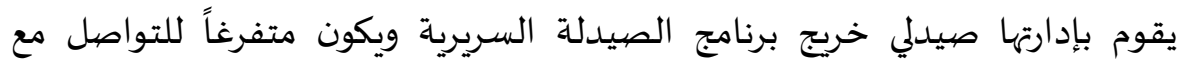

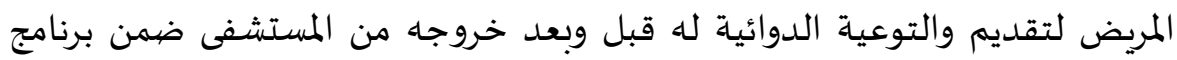
ارشادي معين ع- اعتماد منشورات ارشادية وتوضيحية مبسطة Pill Chart ترفق مع الأدوية التي تصرف للمريض في الصيدليات الخاصة

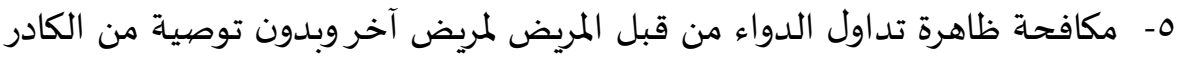

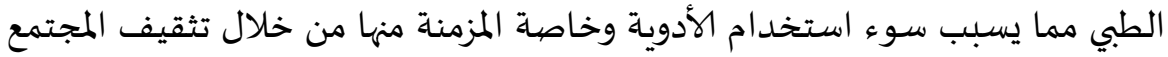

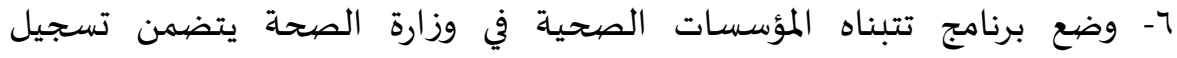
المعلومات المتعلقة كافة بالمريض يتضمن الحالة المرضية والعلاجات التي يستخدمها لغرض توفيرها ضمن نظام يسمى(Patient record system) كما قدم الصيدليالسعوديخالد بن حمزة المدني دليلا علميا بعنوان " انت

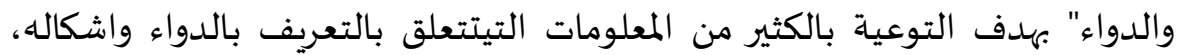

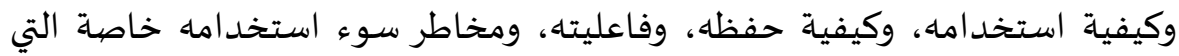


تتم بدون توصية طبية وكيفية تلافيها،وذلك على شكل جرعات تثقيفية تحقيقاً لمفهوم التنور الدوائي Pharmaceutical Literacy.

كما قام مركز تعليم الكبار بجامعاة المنوفية بالتعاون مع كلية الصيدلة

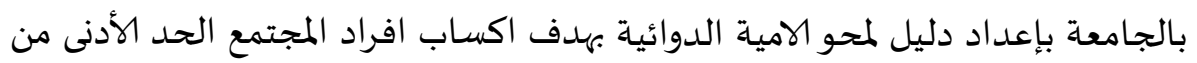

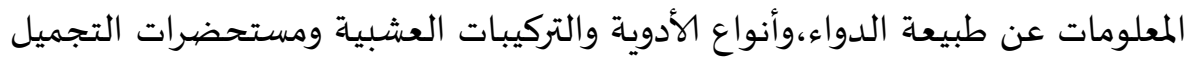

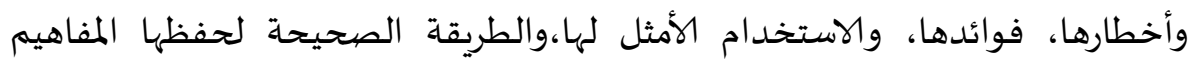

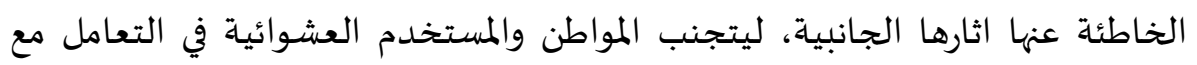
الدواء. اننا في ظل تلك الظواهر السلبية المترتبة على العشوائية في استخدام الدواء في

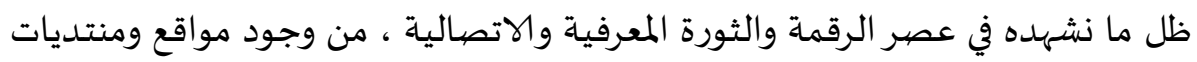

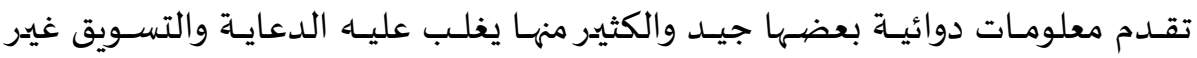

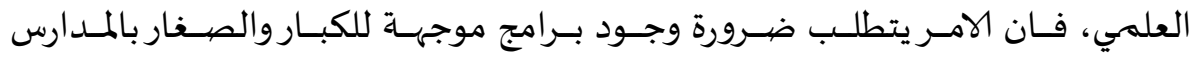

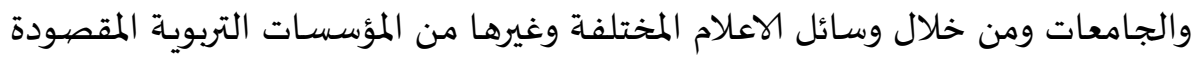

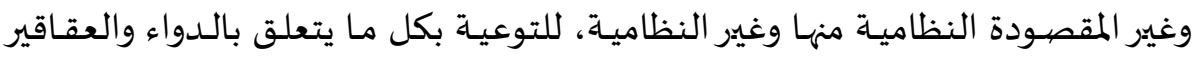

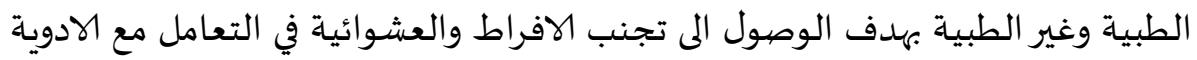

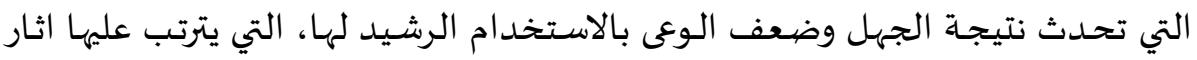

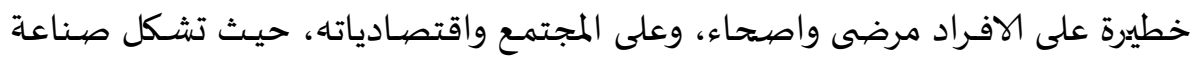

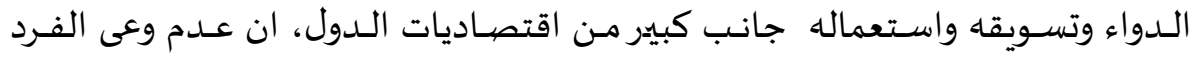
بكيفية التعامل مع الدواء والعقاقير يترتب عليه العديد من المشاكل التي يقع فيها الفرد

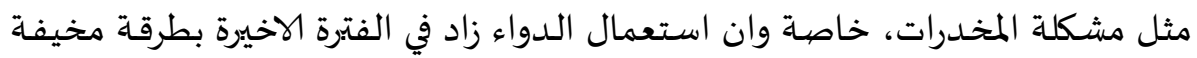

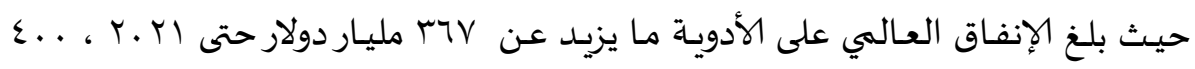

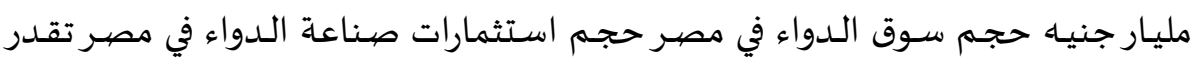

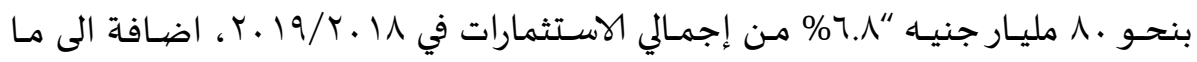

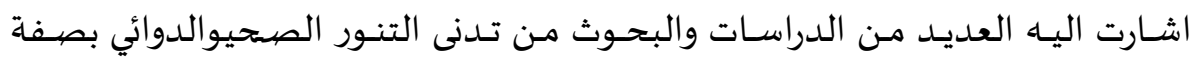

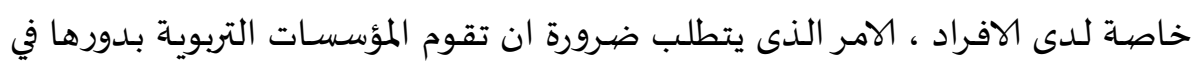

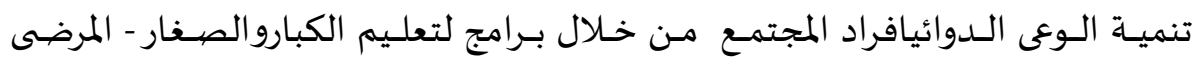


والاصحاء- ، في ظل قصيور الدور الذى تقوم بـه المؤسسـات التعليميـة في هذا المجال، من خلال ما اطلق عليه مصطلح التربية الدوائية وهو ما تسعى الورقة الحالية الى تناوله بله من خلال تناول النقاط التالية : ماليه

- استعراض المقصود بعشوائية استخدام الدواء وأبرز مظاهر تلك العشوائية؟

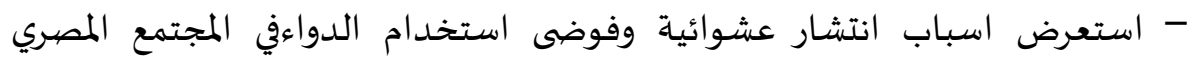
والمخاطر التي يمكن ان تترتب على انتشارها، ومداخل مواجهتها.

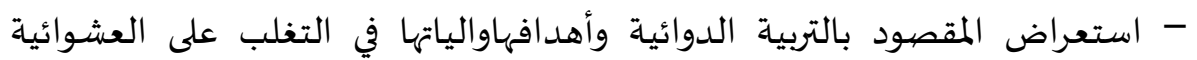
فياستخدام الدواء. - التوصيات والمقترحات لتفعيل دور التربية الدوائية في مواجهة الاستخدام العشوائي للدواء في مصر.

أولا: المقصود بعشوائية استخدام الدواء وأبرز مظاهر تلك العشوائية: الدواء كمنتج يجب عدم اعتباره منتجا تجاريا فحسب وذلك لأن للدواء

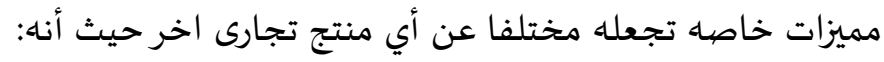
ا- مادة مؤثرة على حياة الانسان فاذا اختفت من الاسواق ليس سهلا تبديلها

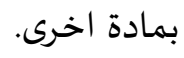
r- لا يمكن للإنسان استبدالها بمحض ارادته بل بوصفة طبيب وليس كالغذاء

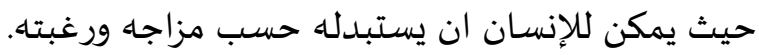
r- الدواء ليس منتجا عاديا ولا يمكن انتاجه بسهولة ال من قبل مختصين وفي مصانع وظروف خاصية. ع- الدواء يخضع للغش كأي مادة اخرى ولكن الغش فيه قد يودي بحياة الناس ويقتلهم او يذهب بصحتهم بدلا من أن يشفيهم.

0- أن ظاهرة الغش في الادوية اصبحت شائعة على مستوى العالم وكلما كانت

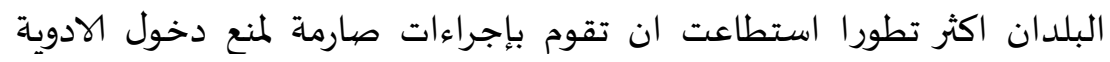
المغشوشة. 
ان الاستخدام غير الرشيد للدواء مشكلة عالمية ولا تقتصر على واصف وصارف

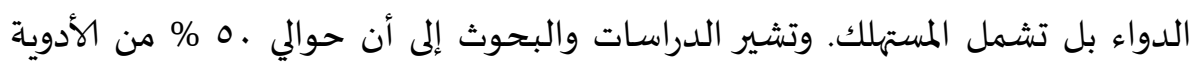

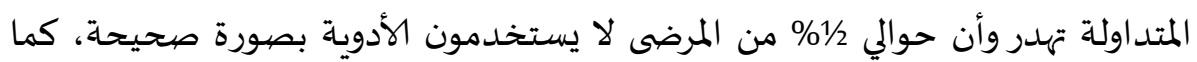

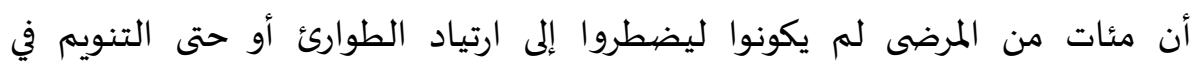

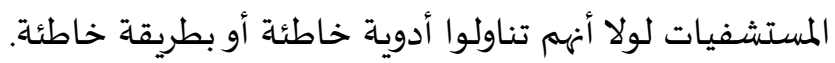

ويعتبر الاستعمال غير الرشيد للأدوية من المشاكل الشائعة والمعقَّدة لتعدُّد

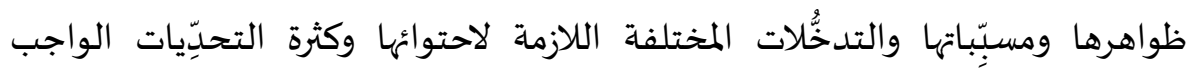
مواجهتها وعظم الجهود الواجب بذلها لترشيد استعمال الدواء.

الواقعأن هناك أربعة أقسام من الأدوية التي تصرف في الصيدلية وهي: ا- الأدوية التي لا تصرف إلا بموجب وصفة طبية مراقبة من وزارة الصحة وغالباً

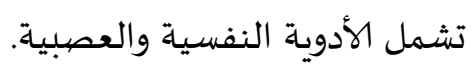

r- الأدوية التي تصرف بموجب نشرة طبية للمرة الأولى فقط ثم يكررها المريض شهرياً دون الوصفة وهذه تشمل، أدوية الضغط والسكري والقلب.

r- الأدوية التي تصرف بوصفة طبية حسب حالة المريض وتشمل أدوية الالتهابات أو

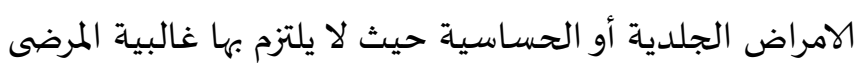

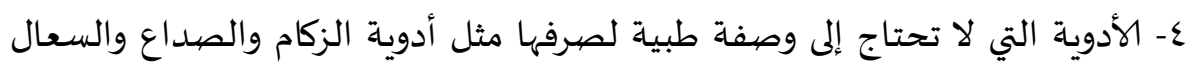
والآلام الخفيفة. المقصود بعشوائية او فوضى استخدام الدواء: العشوائية في استخدام الدواء تعنى عدم استخداء الدواء: استخدام الدواء المناسب،

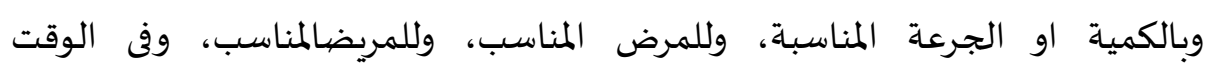
المناسب،والذي يصفه الشخص المناسب، ومن المصددر المناسب.

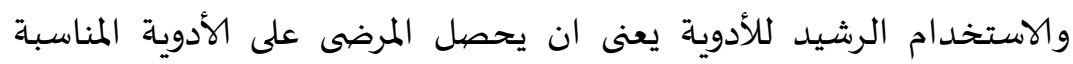

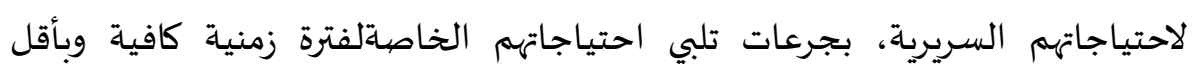
التكاليف لهم ولمجتمعهم. 
مظاهر العشوائية في استخدام الدواء: تتمثل مظاهر عشوائية الدواء فيما يلي:

عدم قراءة التعليمات المرفقة بالأدوية رغم أهمية ذلك لمعرفة الماهية أخطار المحتملة لتناول

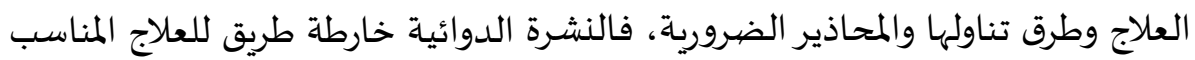
والتوعية الأثار الجانبية لله.

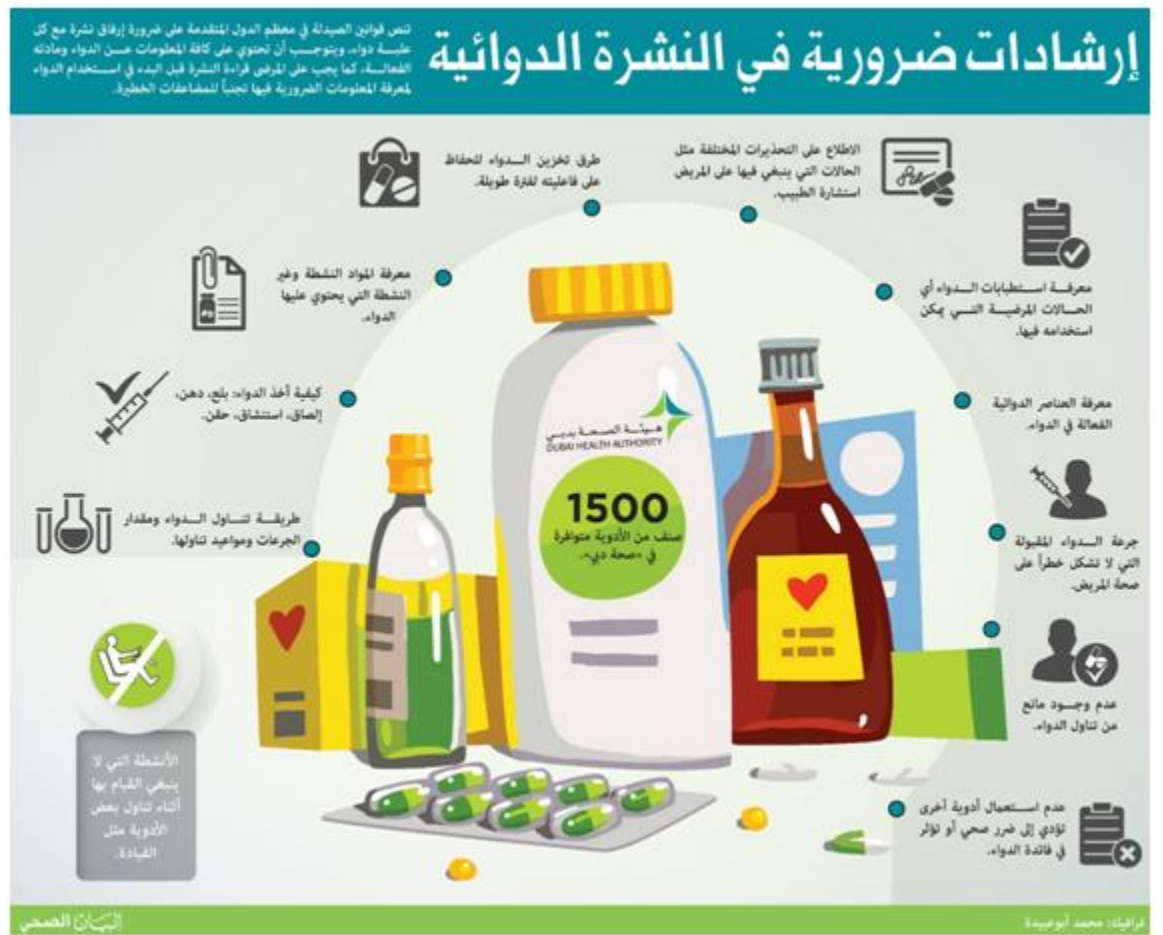

ذهاب البعض إلى أقرب صيدلية أو مخزن أدوية أو حتى محلبقالة، بل وصل الامر الى

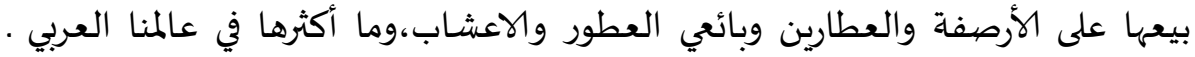
لشراء بعض الأدوية بدلا من الذهاب إلى الطبيب المختص لتشخيص الحالة المرضية وتقرير العلاج المناسب وفقا للحالة.

هناك من يتعامل مع الدواء كسلعة قابلة للبيع والشراء بصرف النظر عن المخاطر الناجمة عن سوء استخدامها على حياة الناس. 
عدم اكمال المريض المدة المحددة للعلاج، وإيقاف تناول العلاج عند تحسن الحالة

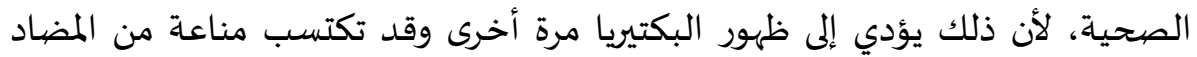

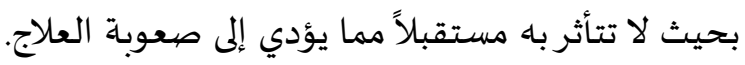

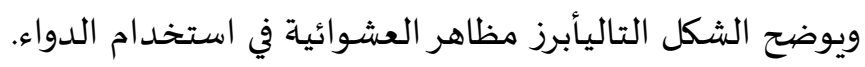

\section{عشوائية استخدام الدواء ، الاستخدام الخاطئ للأدوية}

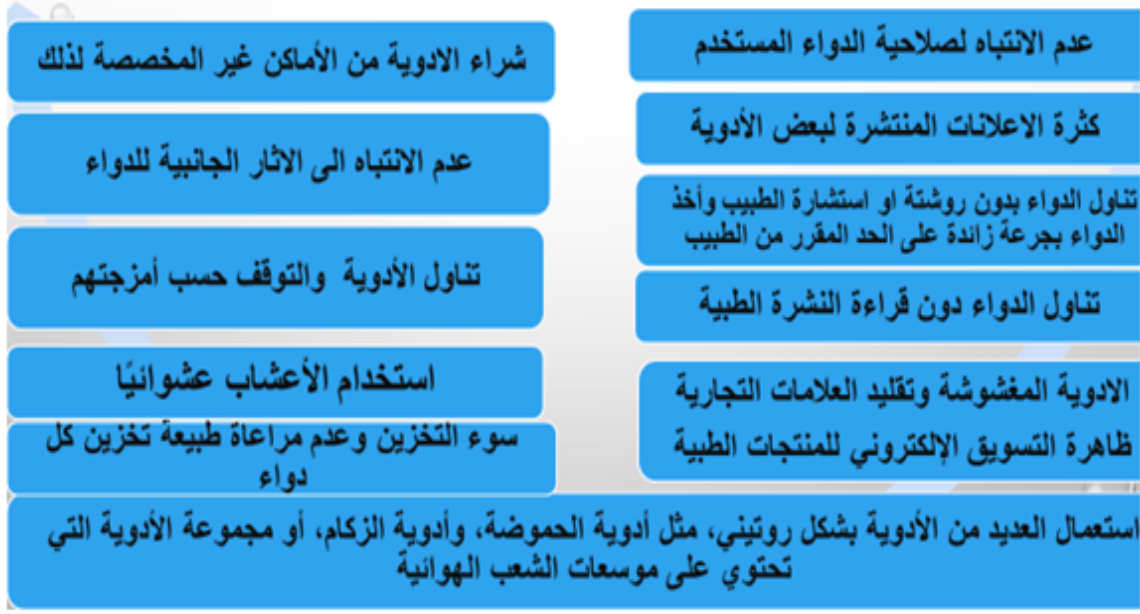

$$
\text { ويمكن شرح هذه المظاهر بشكل أكثر تفصيلا على النحو التالي: انتشـار الادوية المغشوشة' واستخدام افراد المجتمع لها : }
$$

'لكل دواء له إسمان أو ثلاثة، وذلك بحسب مدى إمكانية شركات عدة على إنتاجه

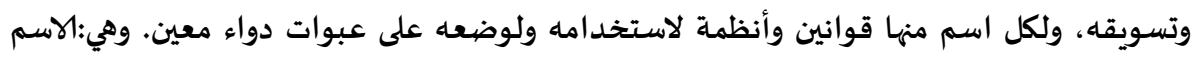

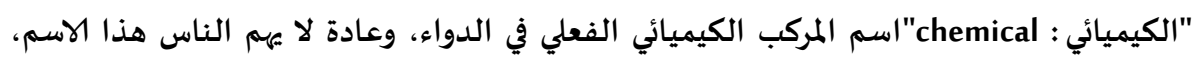

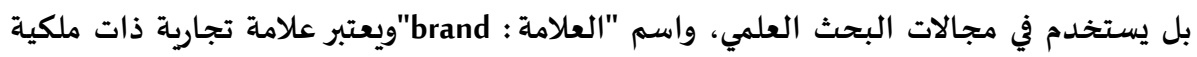

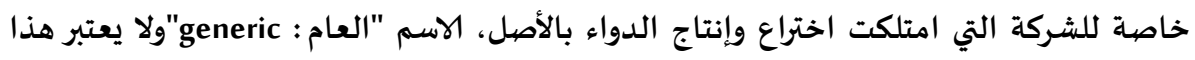
الاسم ملكية خاصهة، ولكنه يدل على الدواء. 
إن مصطلح الدواء المغشوش يستخدم لوصف الدواء الذي ينتجه شخص آخر

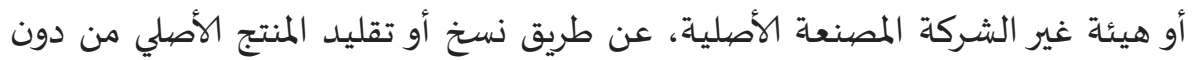

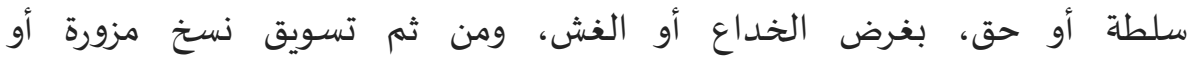

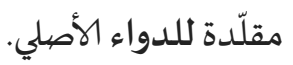

فالأدوية المغشوشة هي تلك المواد التي تباع تحت مسميات غير مرخص بها من قبل السلطات المختصة المخولة بذلك، والغش قد يتضيمن العلامة التجارية للمنتج

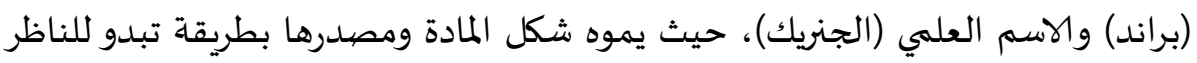

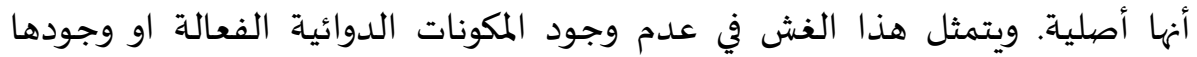

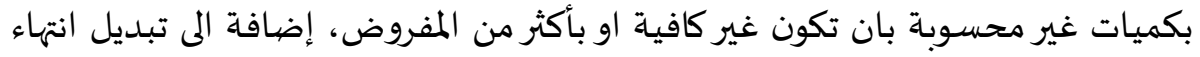

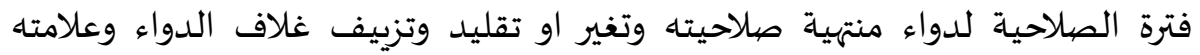
التجارية.

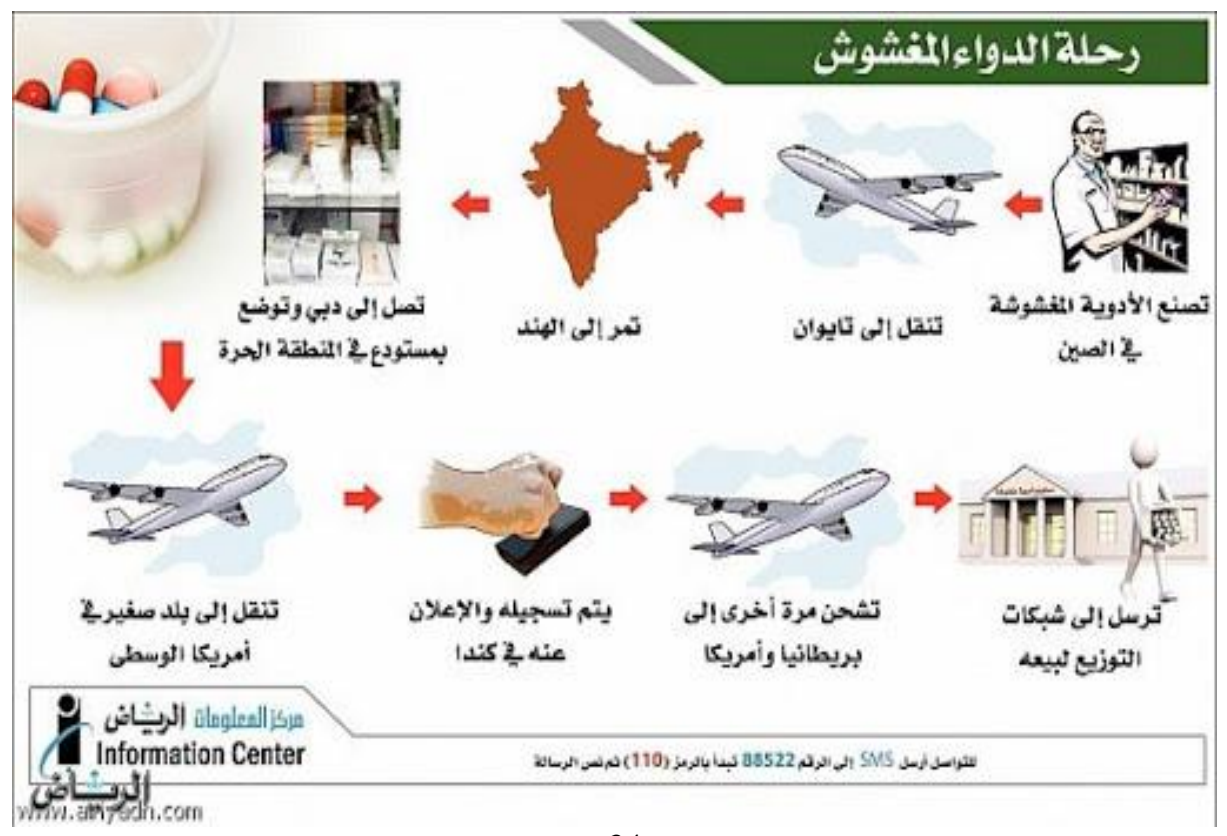


وعلى الرغم من ان غش الادوية مشكلة عالمية كبيرة لكونه شائعا في الكثير

من بلدان العالم ولا يعرف الحجم الحقيقي للمشكلة، وذلك بسبب صعوبة تتبع مهبع الغش لكونه مشكلة كبيرة وتجارة عالمية تدخل فيها مافيات ودول، لا له انها أكثر انتشارا في الدول النامية والفقيرة، فقد اشـارت منظمة الصحة العالمية الى ان مقدار انتشـار الادوية المغشوشة يتراوح بين أقل من ا \% في البلدان المتقدمة وحوالي وحوالي

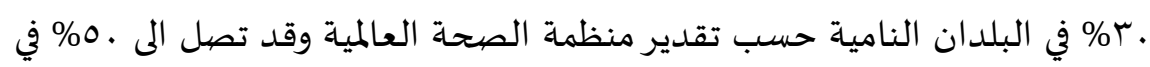

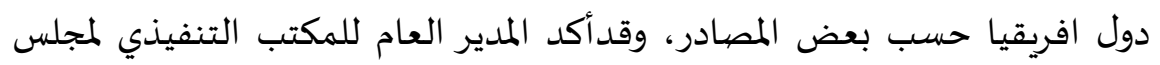
وزراء الصحة لدول مجلس التعاون الخليجي خلال كلمتاه في المؤتمر العربي الثاني للغداء والدواء الذى عقده المكتب في مدينة شرم الشيخ خلال الفترة من الالى ساء ابريل 10 . r ان هب\% من الأدوية المتداولة في الصيدليات.. مخشوشـة.

وتتمثل خطورة غش الادوية في انها قد يؤدي الى الموت،بل موت جماعي للمرضى كما حدث في نيجيريا عام 1990 بسبب دواء يستعمل كمضاد حيوي لالتهاب اغشية الدماغ وكان مزيفا مما ادى الى موت المرضى الذين استعمل في علاجهه.وقد اعتبرته بعض الدول وكثيرا ما نشاهد كأطباء عدم فعالية الادوية في شفاء المرضى كما في المضادات الحيوية او تردي وضعهم الصعي مع استمرار الاستخدام او عدم تسكين الألم بالنسبة للمسكنات او عدم خفض درجة حرارة المريض او عدم فائدة المعقمات والمطهرات مما يؤدي الى زيادة نسب التلوث في الردهات وصالات العمليات.

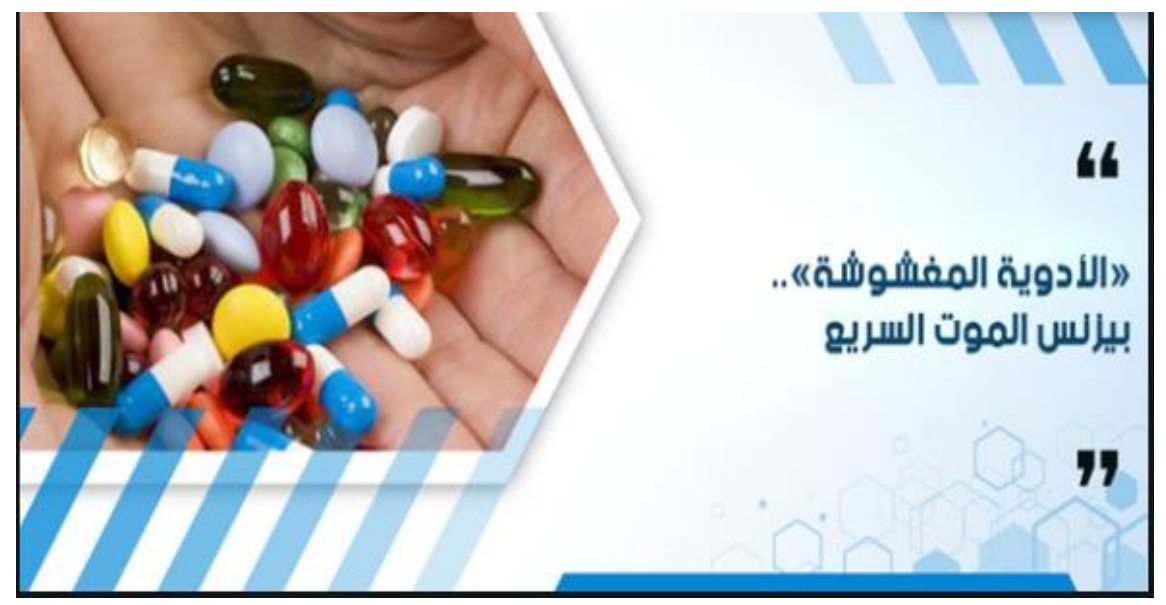


والواقع ان ظاهرة غش الادوية تشكل مشكلة للطبيب والصيدلي والدولة

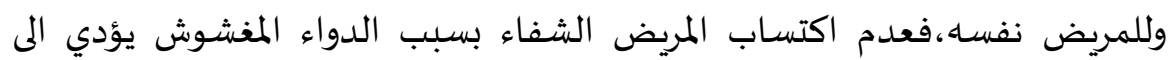

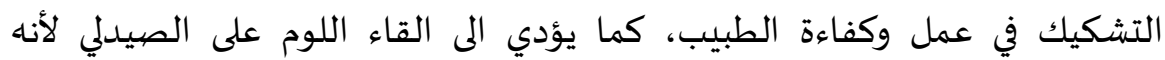

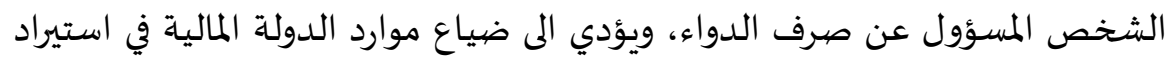

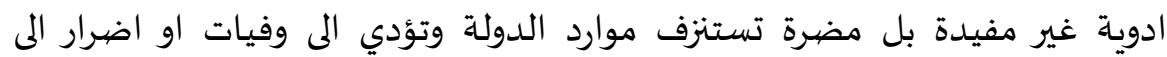

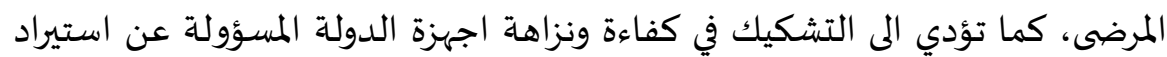
الادوية او فحصها او مراقبتها في المذاخروالصيدليات.

والواقع ان الدواء المغشوش والتعرف عليه ومنعاه هو من مسؤولية الجميع

فالمستهلك عليه الدفاع عن صحته وحياته وماله من خلال ملاحظة تاريخ انتهاء

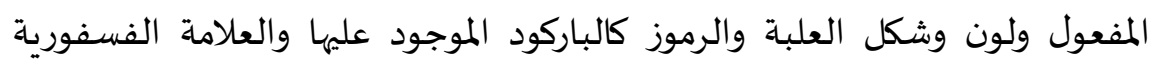

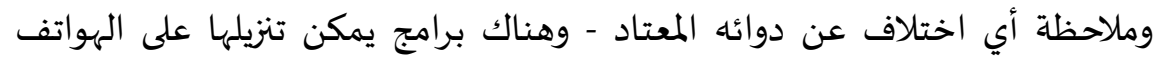

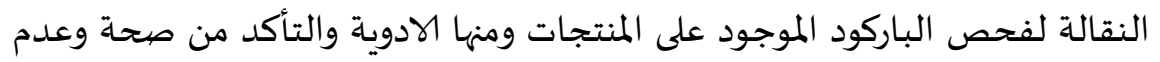

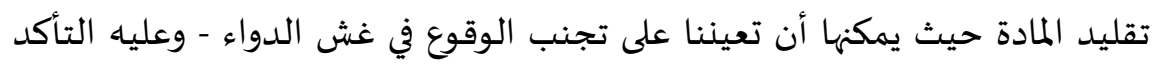

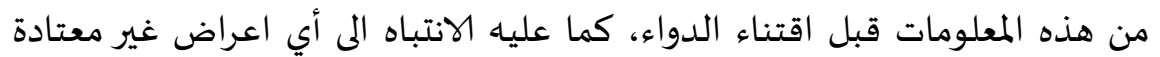

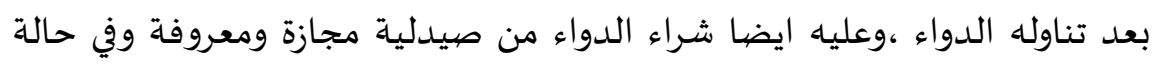
التأخر في اكتساب الشفاء عليه ان يضع في اعتباره امكانية أن يكون الدواء 


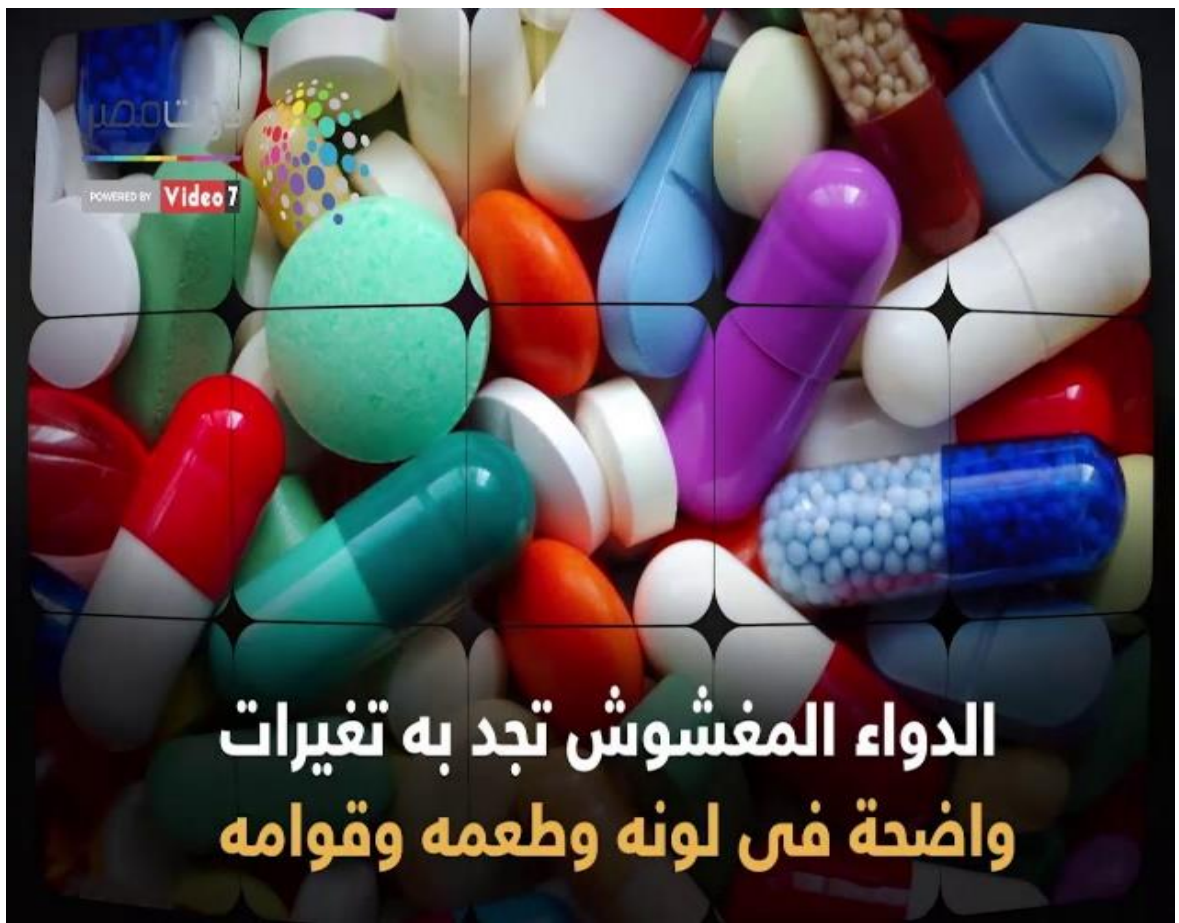

والصيدلي عليه أن يعرف أن هذه مسؤوليته ويتحمل المسؤولية القانونية

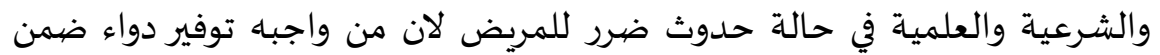

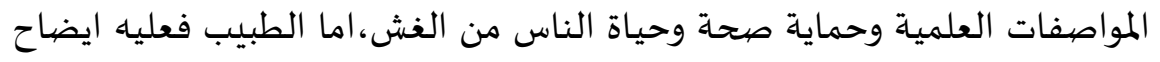

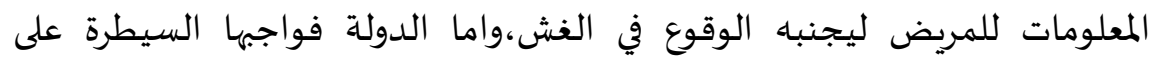

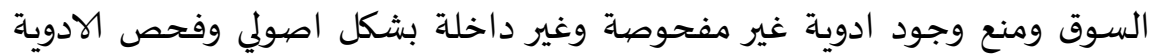
وضبط ومحاسبة تجار الادوية المغشوشة والفاسدة.

\section{r- عدم الاخذ في الاعتبار الاثار الجانبية للدواء:}

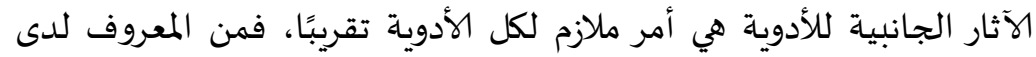

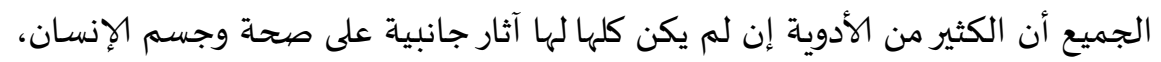

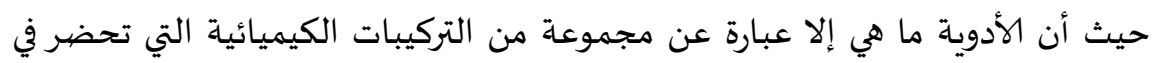

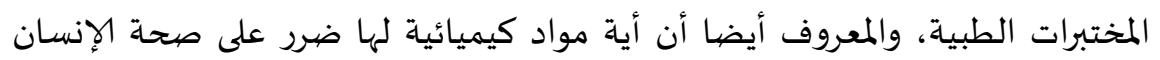

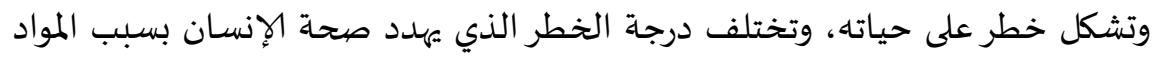

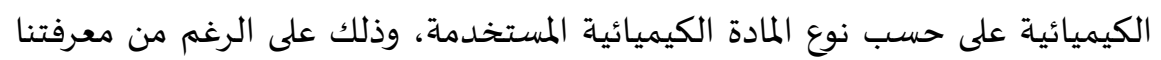


جميعا أن الأدوية الطبية تستخدم في علاج الإنسان من مرضها ولكن أيضا في نفس آلتس

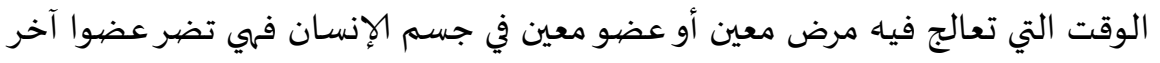

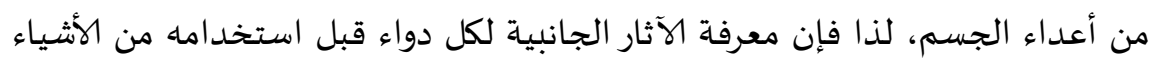
ذات الضرورة القصوى في حياة كل إنسان.

هناك نوعين من الآثار الجانبية للأدوية حيث يتم تقسيمهم إلى أعراض

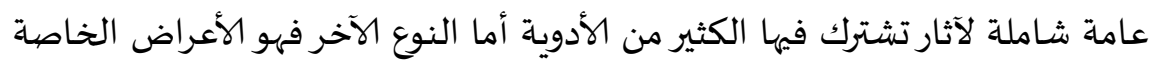

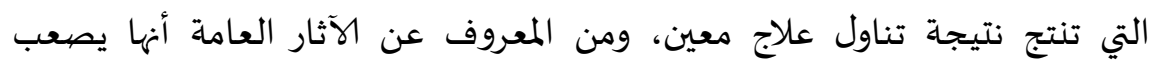

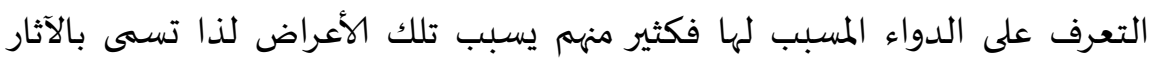
العامة على عكس الخاصة التي تخص دواء بعينه، كما ان هناك نوع آخر من الآثار

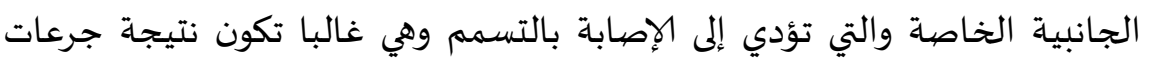

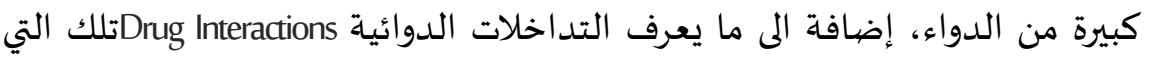

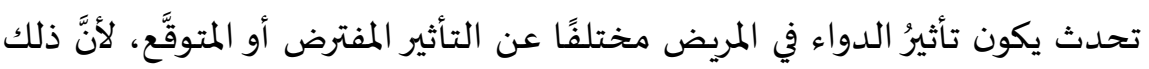

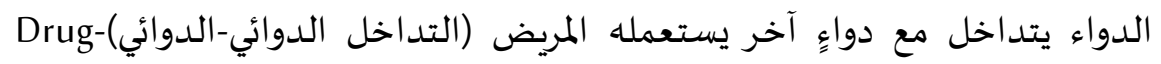
Drug Interactions المريض (التداخل الغذائي الدوائي) Drug-Nutrient Interactions، مرض الخدون آخر يعاني

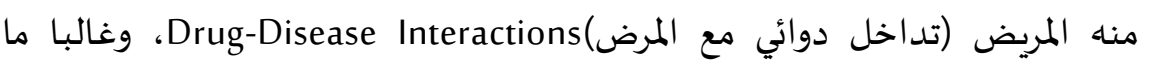

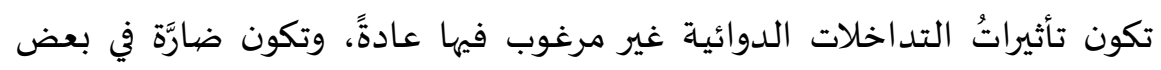

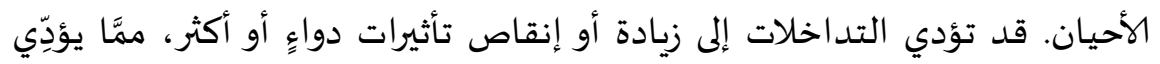

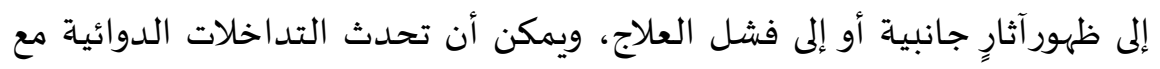

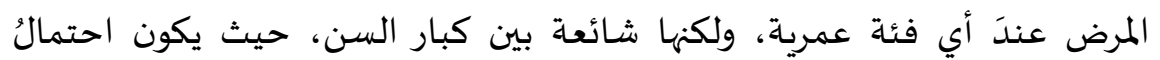
إصابتهم بالأمراض أكبر) . 
الشكل التالي يوضح أبرز الأثار الجانبية لعقار الكورتيزون على كل أعضياء الجسم

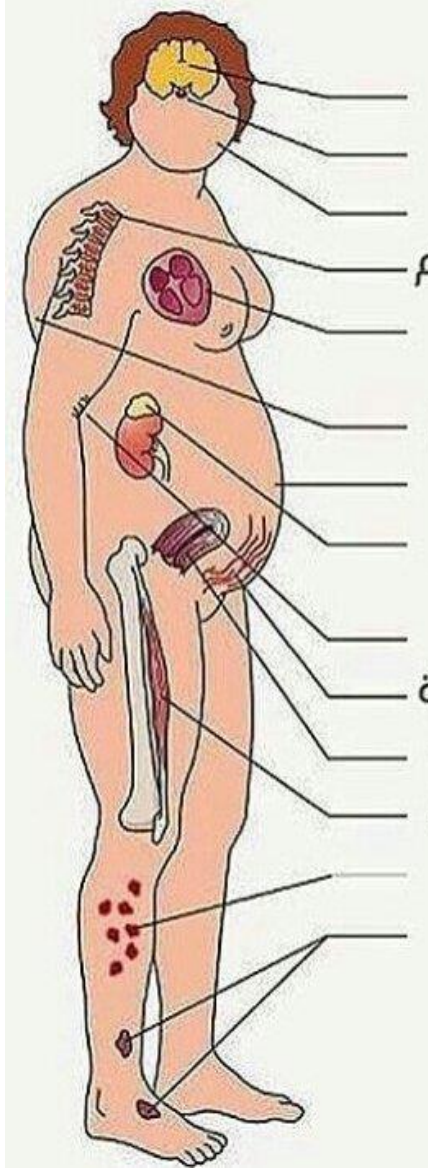

تقلب المزاح

ضمور الغدد

وجه القمر هشاشة العظام القمر

تضخم القلب

تقوس الظهر

السمنة

أضرار بالكلى

بقع الجلد

التشققات الجلدية

أضرار العلاجح

بالكورتيزون

انقطاع الطمث الطفات الجمفي

ضعف العضلات

طفح جلدي

قرح القدم

وعلى الرغم من إن التعرف على الآثار الجانبية لكل دواء من الأمور الصعبة،

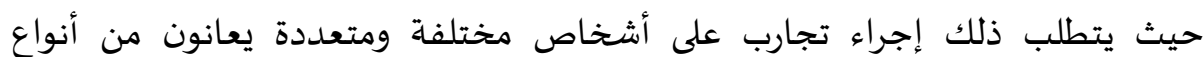

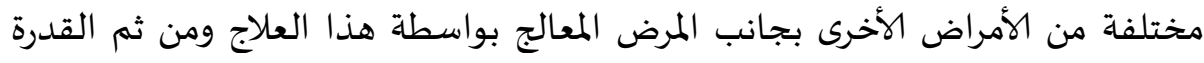

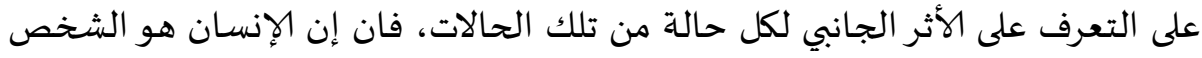

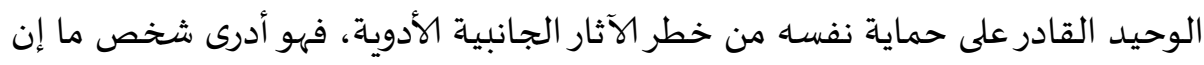

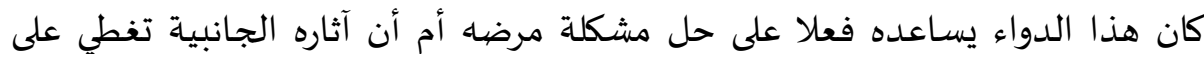

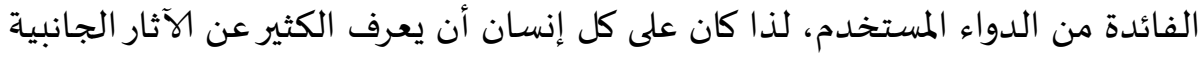




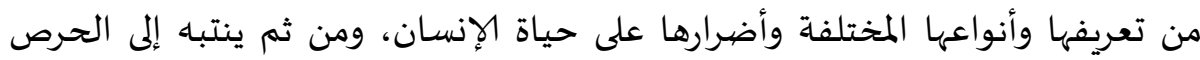

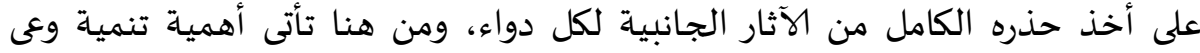
الافراد بتلك الاثار قبل تعاطى الدواء.

\section{r- استخدام الادوية منتهية الصلاحية Expiredmedication:}

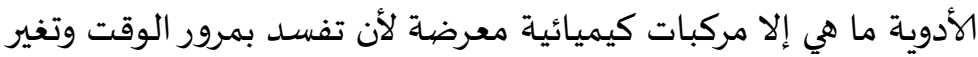

الظروف المحيطة ولذلك ومنذ عام 19V9، وإدارة الغذاء والدواء الأمريكية (FDA) تُلزم شركات الأدوية أن تضع تواريخ انهاء الصلاحية على جميع الأدوية سواء كانت

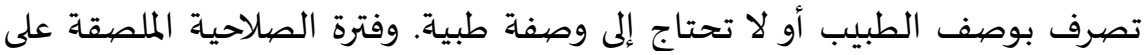

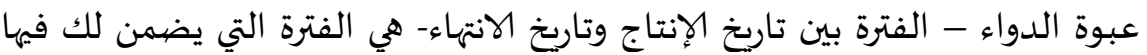

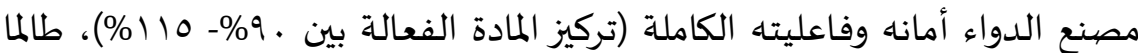
يتم تخزينه بالطريقة المبينة على العبوة؛ أي أنه في الوقت الذي لا يعني فيه انتهاء

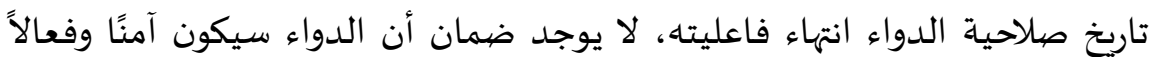
بعد انتهائه. - مبر.

فقلما يخلو بيت من أدوية غير مستخدمة أو زائدة عن الحاجة، فغالبا ما

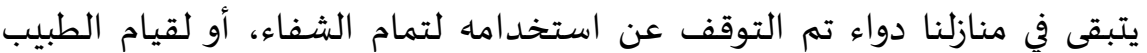
بتغيير الدواء المستخدم، أو لانتهاء تاريخ صلاحيته فلا يمكن استخداءماه.

وقد كشفت هيئة الدواء والغذاء عن ع عوامل تمثل خطرًا عند تناول أي

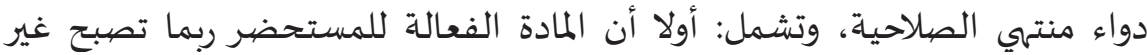
مستقرة كيميائيا، وثانيا فعالية الدواء قد تتغير، وثالثا تحلل الدواء قد ينتج مواد

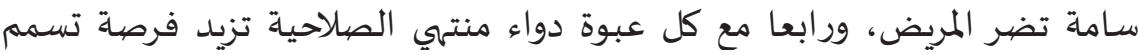
الدواء، وأشارت الى أن بعض المض الأدوية تتكون من مواد كيماوية مع انتهاء مدة دواء ملاحيتها

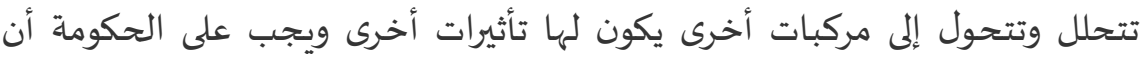
تتدخل لدى الشركات لإجبارها على سحبها من الأسواق لحماية المواطنين.

ومما يزيد من خطورة تلك الظاهرة ان التخلص من الأدوية غير المستخدمة،

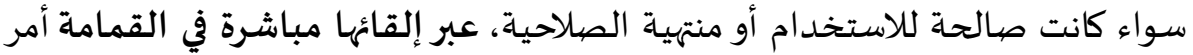


فائق الخطورة، وذلك على الرغم من شيوعه، حيث إن ذلك يعرض تلك الأدوية لإعادة

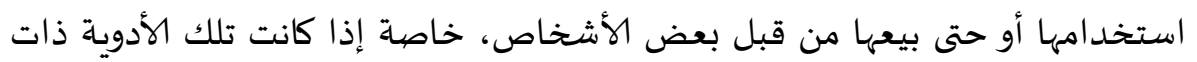

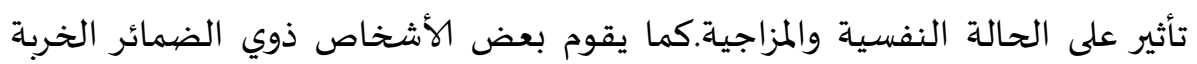

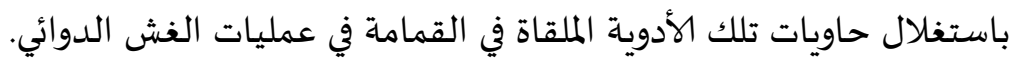

كما ان -التخلص من الأدوية عبر سكبها في المراحيض أو الأحواض أمر ذا

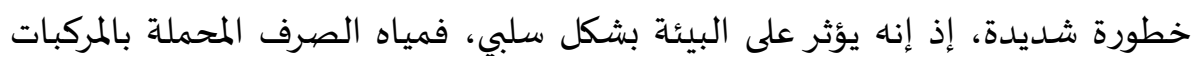

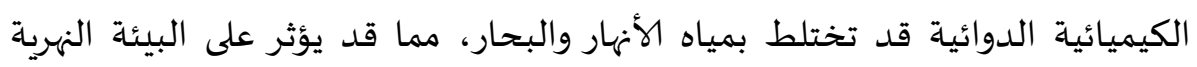

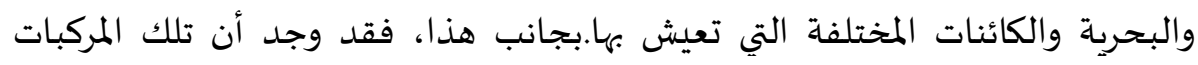

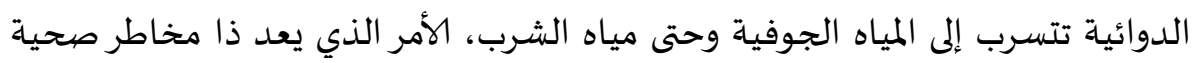
عديدة.

أن الأدوية منتهية الصلاحية إما تُباع في السوق أو يُعاد تدويرها في مصانع "لبئر

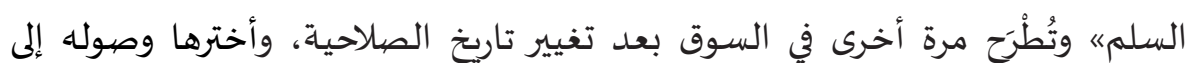

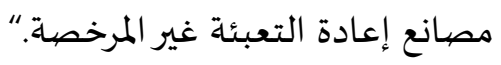

ويُعدّ إعطاء الأدوية الزائدة عن الحاجة لأشخاص آخرين، أو التبرع بها، من

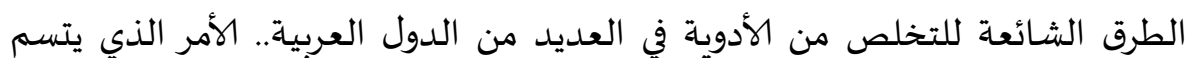

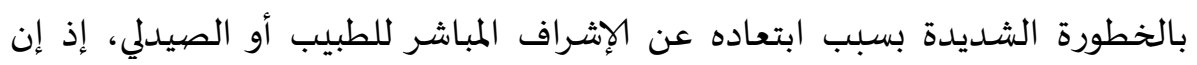

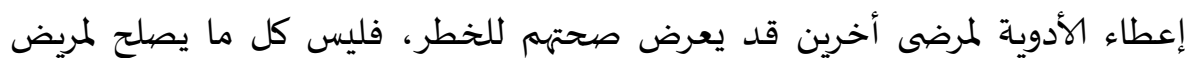
بعينه قد يصلح لمريض آخر حتى ولو تشابهت الحالة المرضية.

ومما تجدر الإشـارة اليه ان تاريخ الصلاحية المبين على العبوة يختلف عن صلاحية

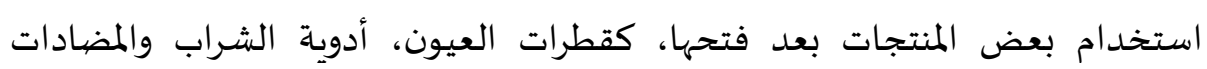

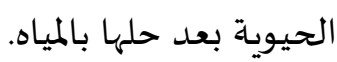

وهناك من يرى ضرورة توخي الحذر الكامل قبل تناول الدواء منتهي

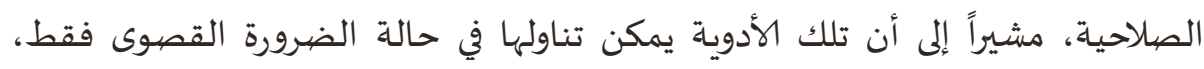

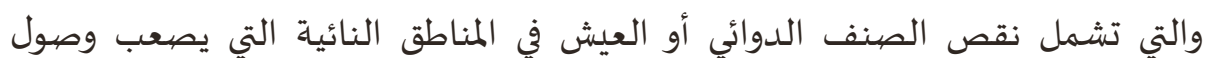

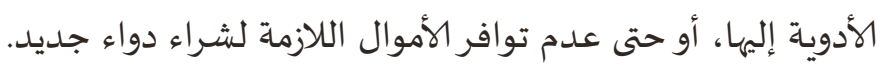


والواقع انالأدوية منتهية الصلاحية أزمة لا تواجه فقط المرضى بل تواجه ايضا

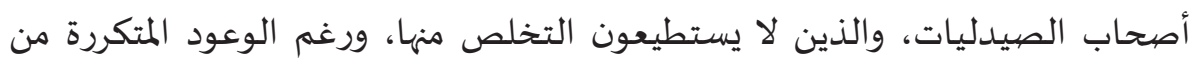

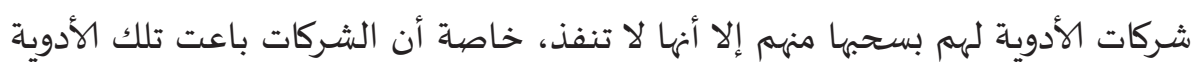
وحصلت على ثمنها مقدمًا.

إن مواجهة تلك الظاهرة تتطلب ضرورة توعية أفراد المجتمع من خلال

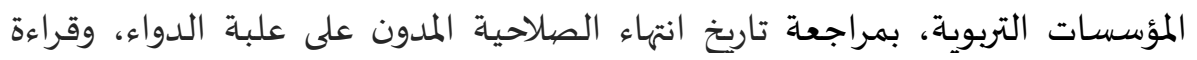

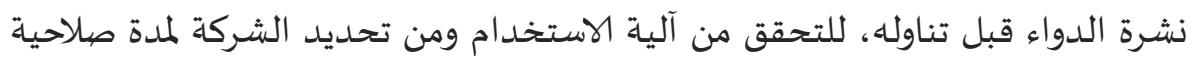
محددة بعد فتح العقار، التخلص من الأدوية منتهية الصلاحية، او في حالة طرأ عليها لون أو رائحة مختلفين.

ع- استخدام الادوية بشكل روتيني ومفرط وبجرعات زائدة: ويتمثل ذلك في استعمال العديد من الأدوية بشكل روتيني، مثل أدوية

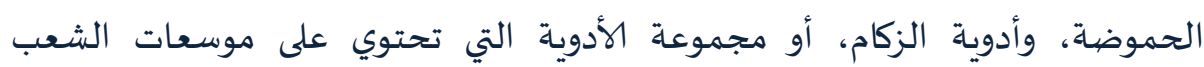

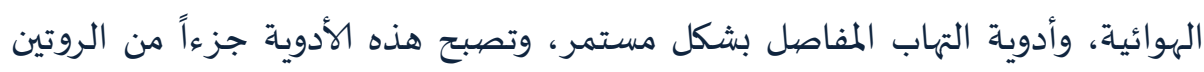

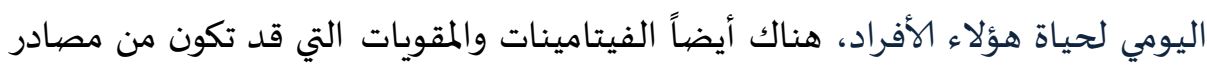

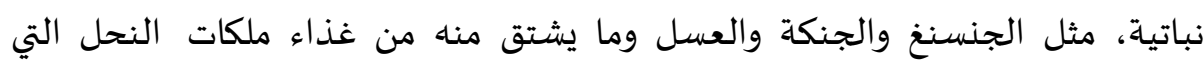

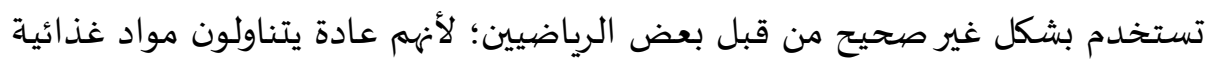
تحتوي على معظم العناصر الغذائية، ومن ثم فإن تناولهم للفيتامينات أمر لا داعي له له لزيادة مقادير هذه الفيتامينات عن حاجتهم اليومياة.

ولعل من اكبر مظاهر العشوائية في استخدام الدواء في مصر، الاستخدام

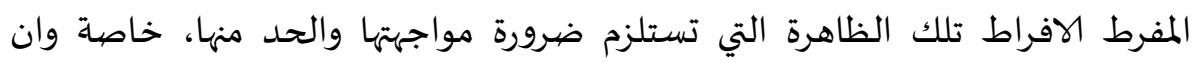

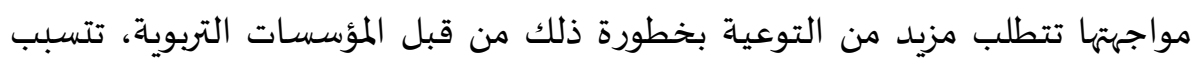

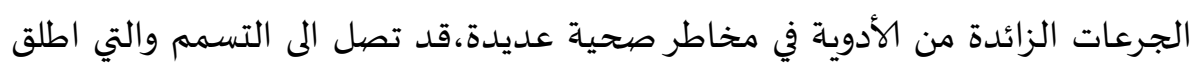


عليها سُمِيَّة الجرعة الزائدة'، وقد تهدد الحياة، فقد ارتفعت الوفيات الناتجة عن الجرعات

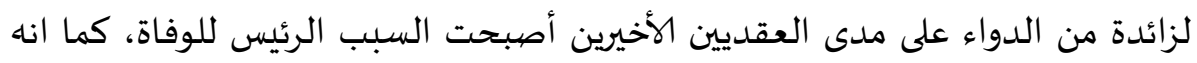

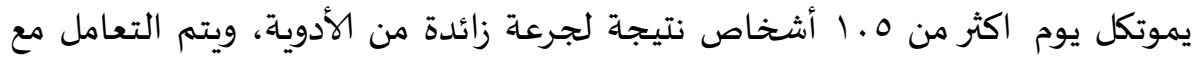

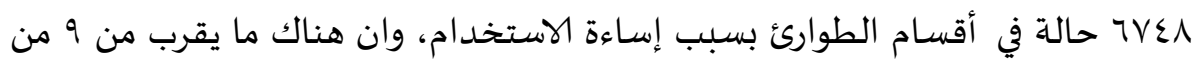
أصل • ا حالات وفاة سببها التسمم الدوائي.

وفى هذا الإطاراكدت منظمة الصحة العالمية. على ارتفع معدل الجرعات

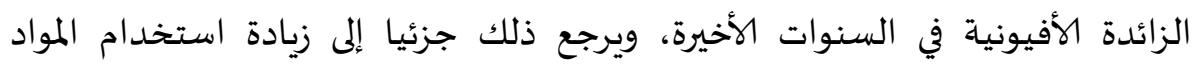

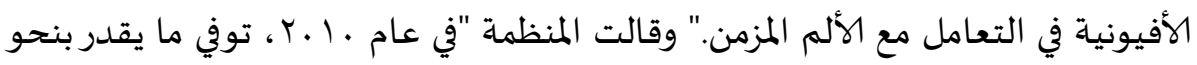

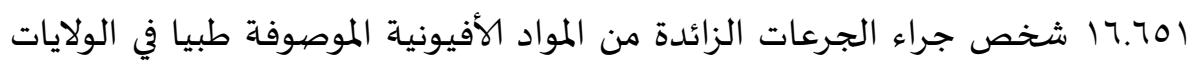

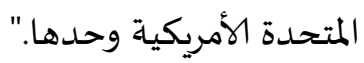

ويعد الرياضين من اكثر الفئات تأثرابنتائج الاستخدام المفرط في الادوية

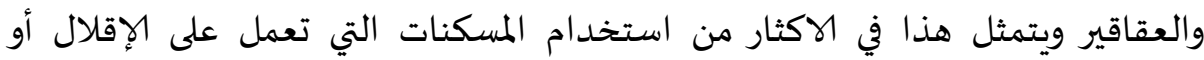

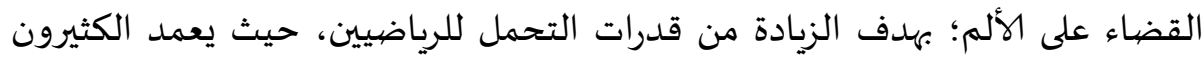

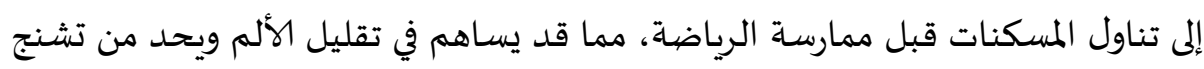

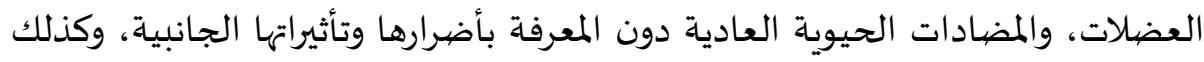

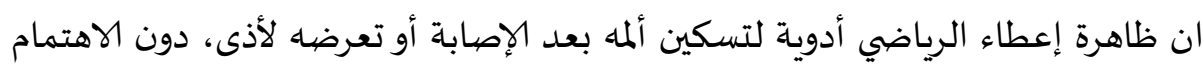

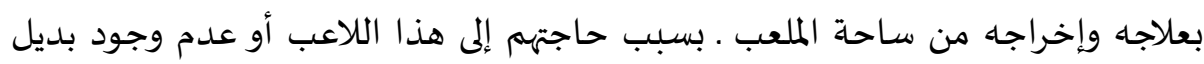

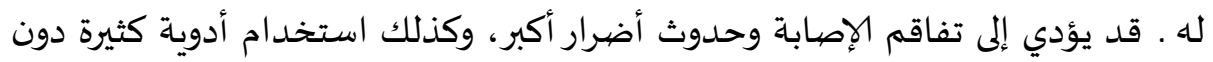
تشخيص أو وصفة طبية؛ بغرض علاج الإجهاد الجسماني أو الشد النفسي، هناك أيضياً

بُشيَير مصطلح سميَّة الجرعة الزائدة Overdose toxicity إلى ردَّات فعل سامَّة خطيرة، ومؤذية

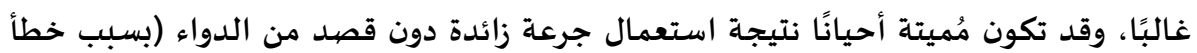

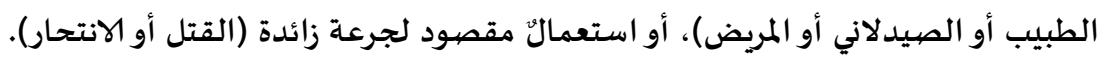

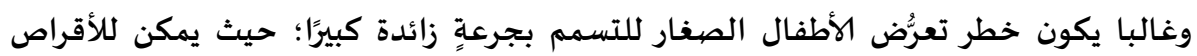

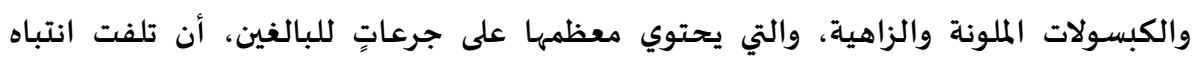

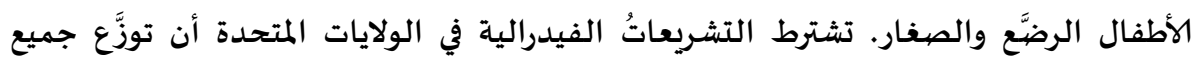
الأدوية الموصوفة المُستعملة عن طريق الفم في عبواتٍ عصيَّة على الأطفال. 
الفيتامينات والمقويات التي قد تكون من مصادر نباتية، التي تستخدم بشكل غير صحيح

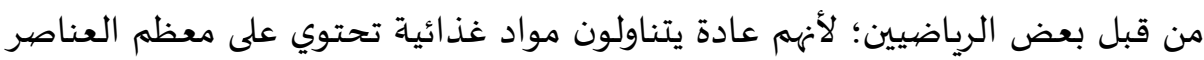

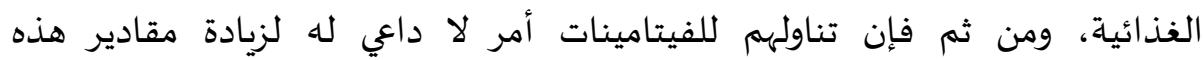
الفيتامينات عن حاجتهم اليومية.

$$
\text { 0- العشوائية في صرف الادوية وبيعها: }
$$

كثيرا ما يغفل البعض أن يكلف نفسه عناء قراءة التعليمات المرفقة بالأدوية بّرغم

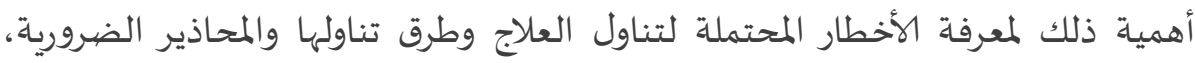

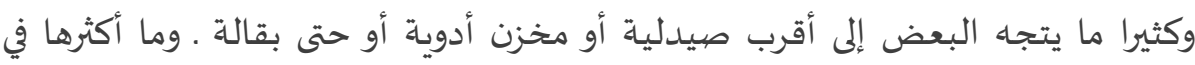

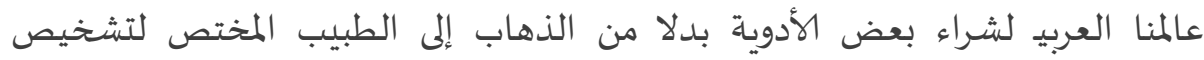

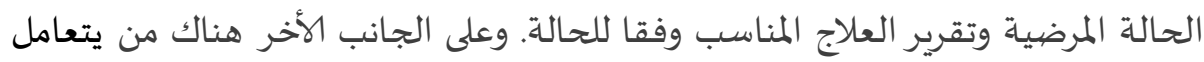

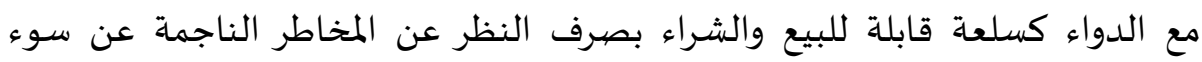

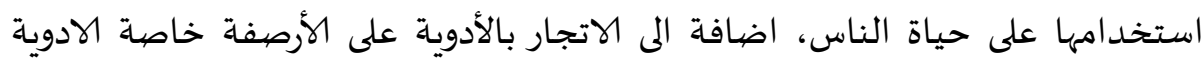
منتهية الصلاحية والمغشوشـة.

إن هذه الواقعة نتيجة التخاذل في سحب الأدوية منتهية الصلاحية من الأسواق،

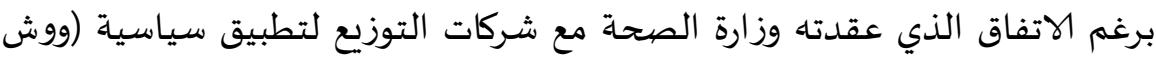

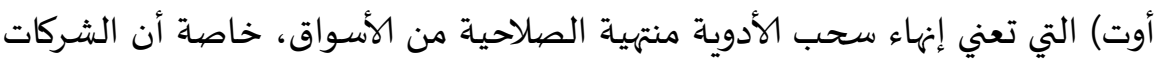
لا تسحب إلا القليل من الأدوية منتهية الصلاحية.

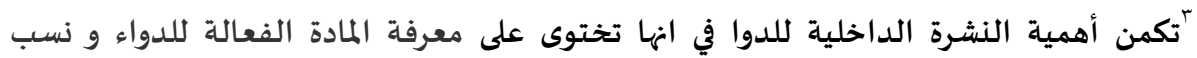

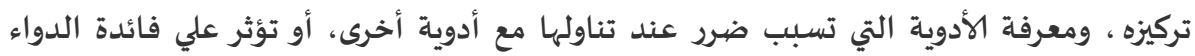

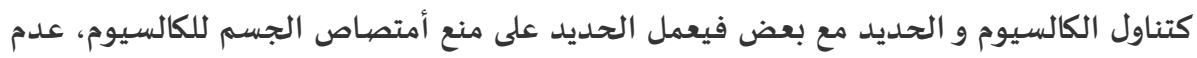

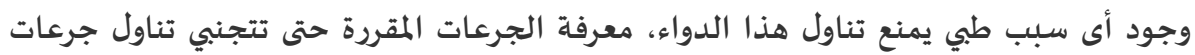

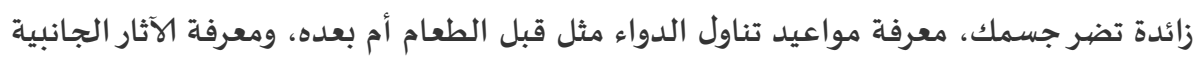
للدواء ولكن لا يجب القلق منها فهي تحدث بنسب قليلة جداً لبعض المرضى فهي للعلم. 
ثانيا: اسباب انتشار عشوائية وفوضى استخدام الدواء في المجتمع المصري والمخاطر

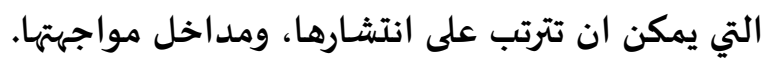

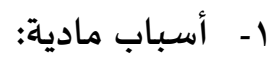

إن الظروف المعاشية الصعبة التي تمر بها شريحة واسعة من أبناء المجتمع

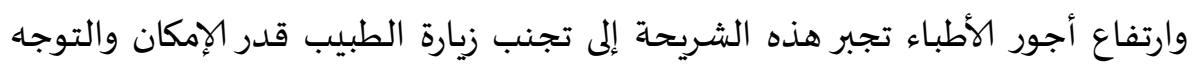

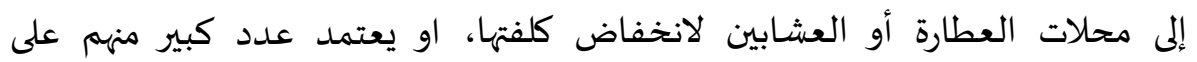

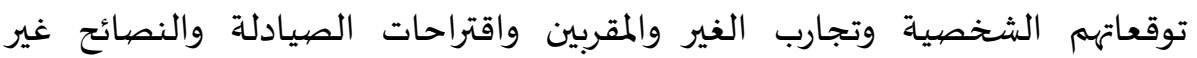

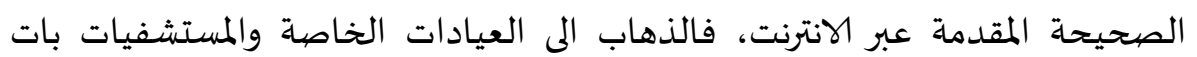
مكلف للغاية.

حيث تخطت غالبية الصيدليات المصرية دورها في بيع الدواء لتصبح

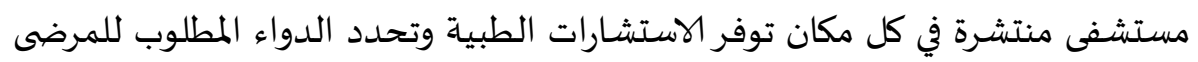

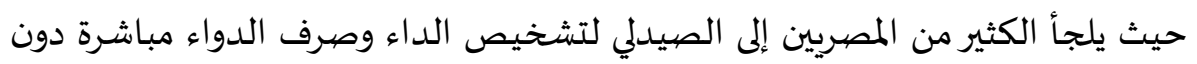

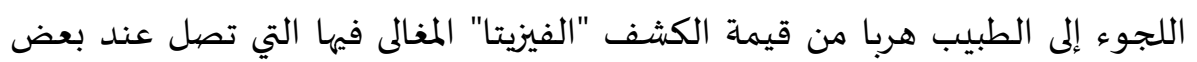

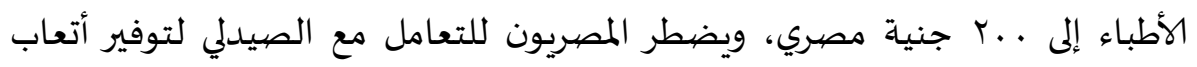

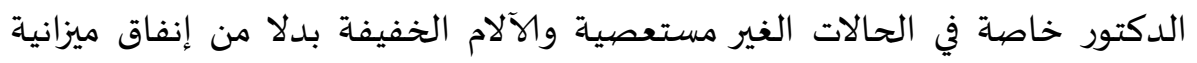
الأسرة في عيادات كبار الأطباء.

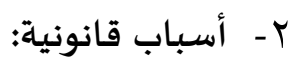
ان عدم تطبيق القوانين المنصوص عليها في نقابتي الأطباء والصيادلة وأهمها التزام الصيدلي بعدم صرف الدواء من دون وصفة طبية، وفى هذا الاطار اكد مؤتمرات

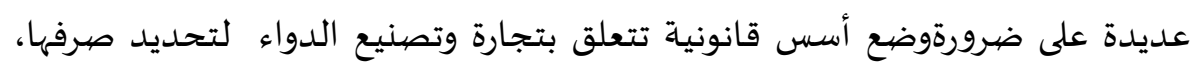

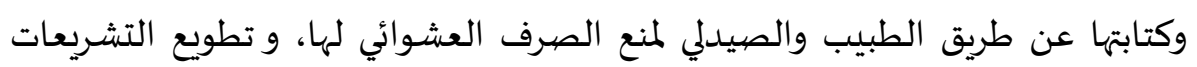

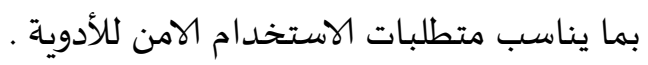

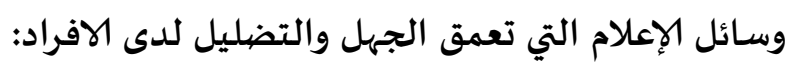
حيث يشهد سوق الإعلانات عن الادوية في مصر حالة من الفوضى، على الرغم

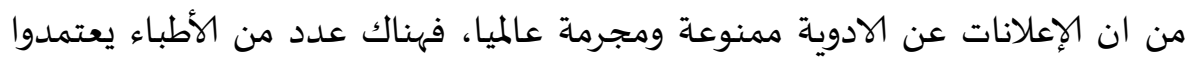


على شراء فقرة في التليفزيون للإعلان عن الادوية غير المسجلة بوزارة الصحة والسكان

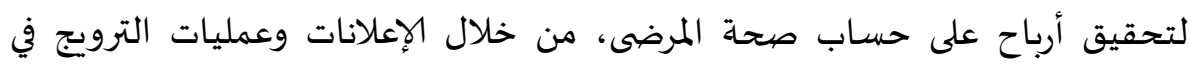

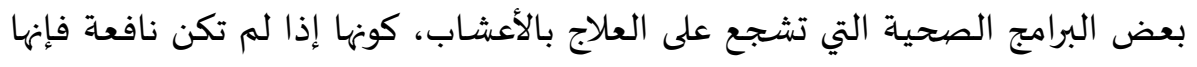

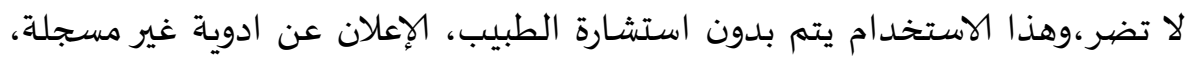

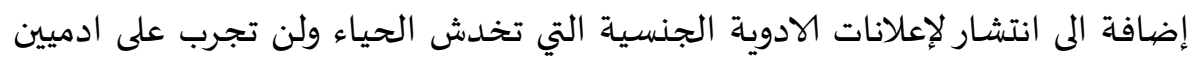
مسبقا،في غياب واضح لدور الدولة لحماية الصحمة العامة. على الرغم من انه توجد قواعد تمنع عرض مثل تلك الإعلانات ولا يوجد

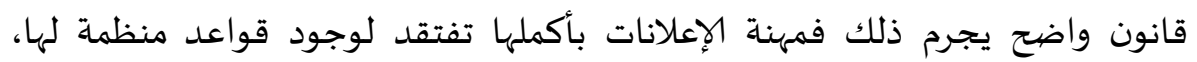

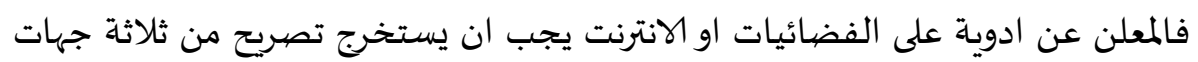

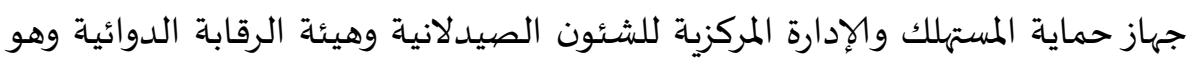

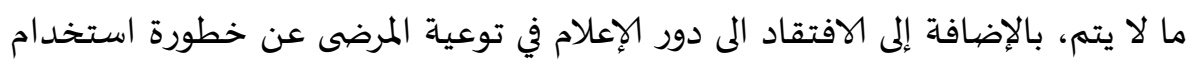

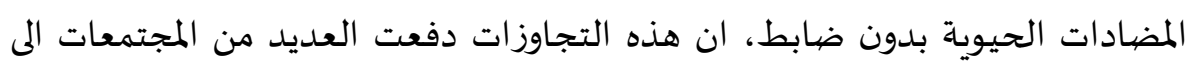
وضع قوانين و مدونات لتنظيم معايير وعمليات للترويج الدوائي. ا - احتفاظ بعض المرضى بالأدوية الزائدة عن حاجتهم لاستخدامها في علاج امراض

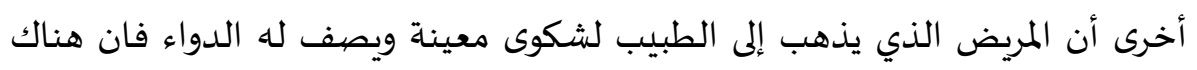

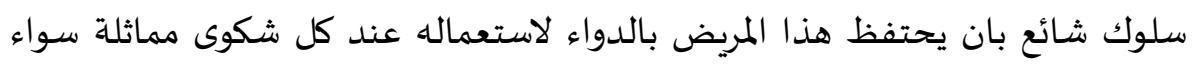
له أو لغيره من الأفراد وهذا سلوك شائع يؤدي إلى أضرار خطيرة.

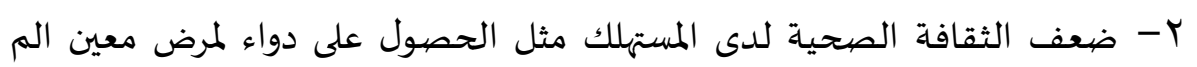

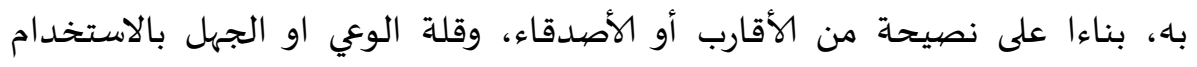

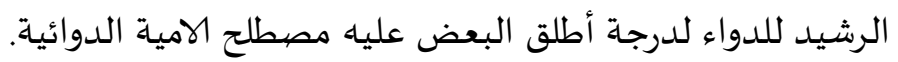

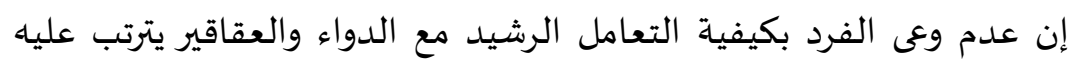

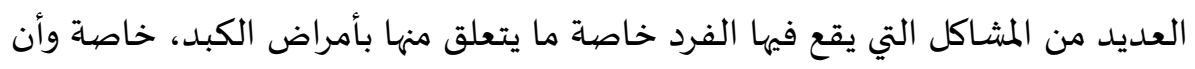

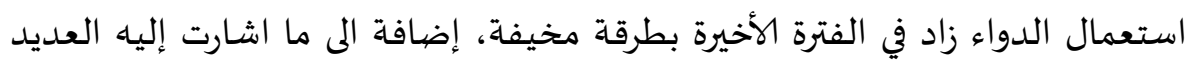

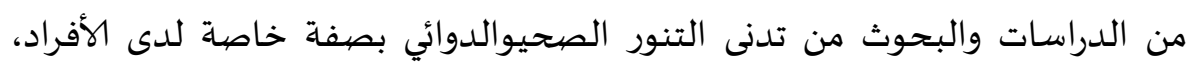
الأمر الذى يتطلب ضرورة تنمية الوعى الدوائي او ما يطلق عليه محو الامية الدوائية 
(التنور الدوائي) لديهم من خلال برامج لتعليم الكبار والصغار- المرضى والأصحاء- ، في ظل قصيور الدور الذى تقوم به المؤسسات التعليمية في هذا المجال.

ثالثا تعريف التربية الدوائية والياتها في التغلب على العشوائية في استخدام الدواء:

ان علاقة التربية بالصحة علاقة وثيقة ومتواصلة، اذ تؤثر الواحدة في الأخرى

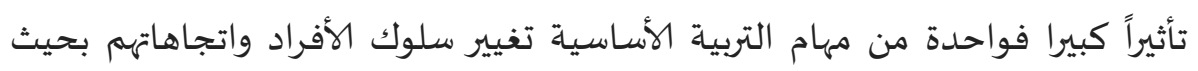

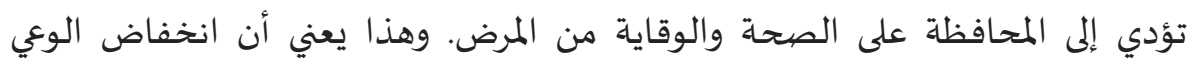

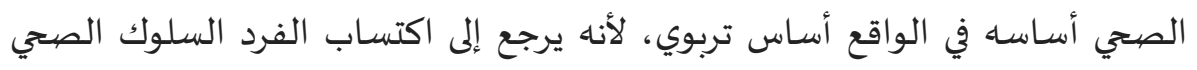

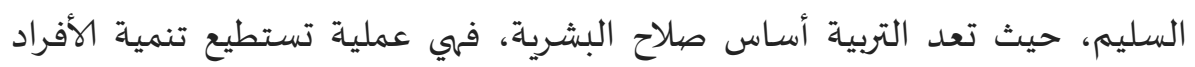
وصقل مواهبهم وشحذ عقولهم وأفكارهم وتدريب أجسامههم وتقويتها.

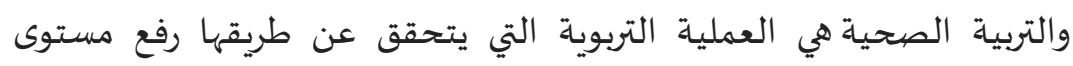

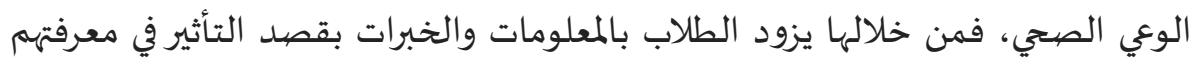

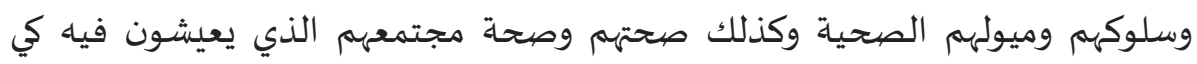

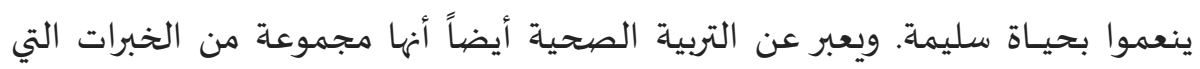

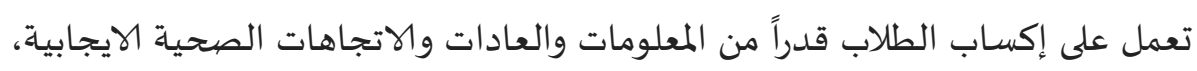

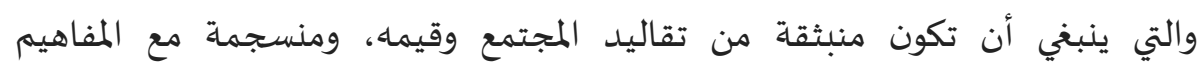

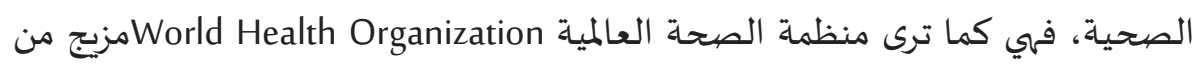

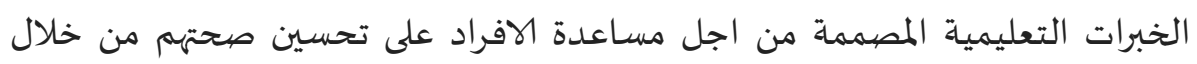

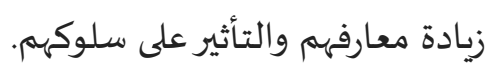

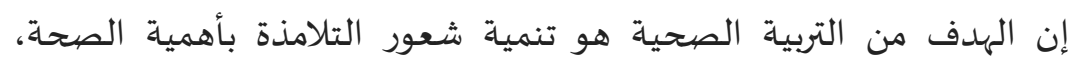

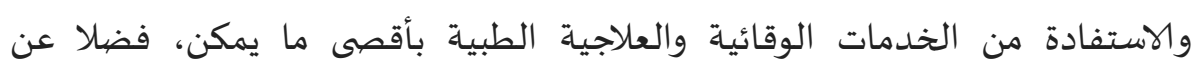

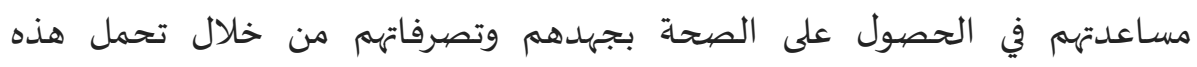

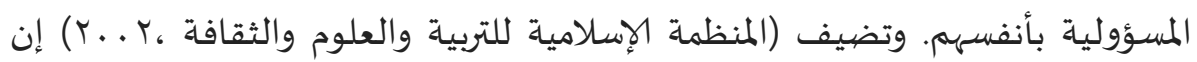
التربية الصحية تسعى إلى تنشئة التلامذة تنشئة صحية شاملة، تساعدهم على المانى مواجهاة

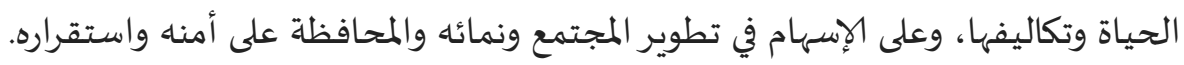


وعموماً فالتربية الصحية تهدف إلى إكساب الطلاب ثقافة صحية عامة، والتي

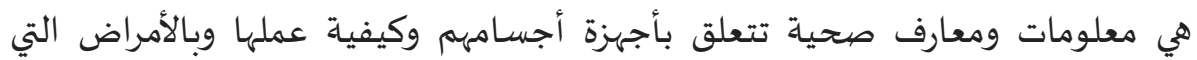

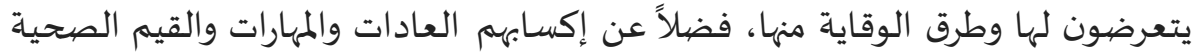

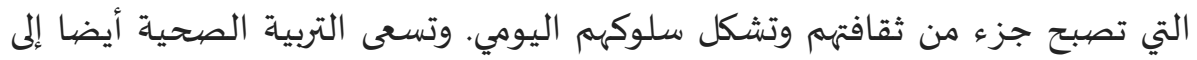

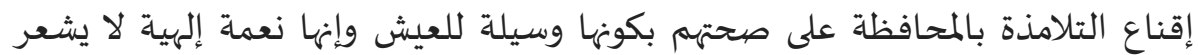

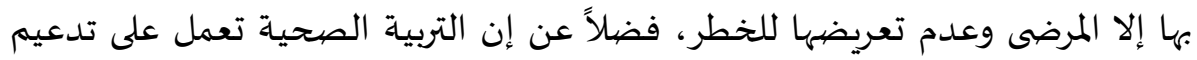
الوعي الصحي والغذائي وتعزيز حس التلامذة الوقائي. ومع انتشار وباء فيروس كورونا في العصر الحالي فان العناية بالتربية الصحية الصداتية

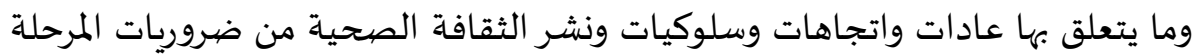

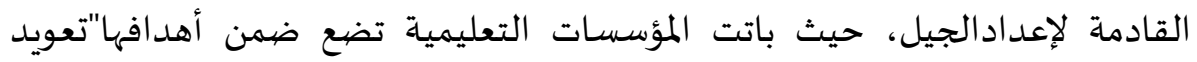

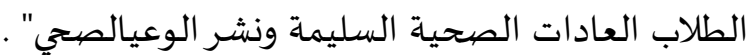

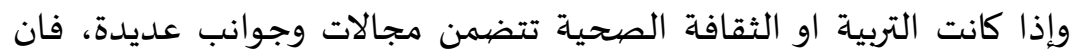

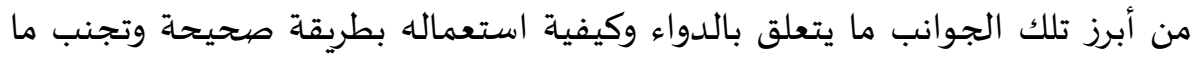

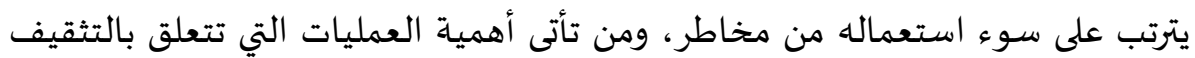
الدوائي او التنور الدوائي Medicinal literacy او ما أطلق على عليه التهبه التربية الدوائية. واذا كانت الامية تعنى مؤنث الأمي وهى لغة تغنى الغفلة او الجهالة، او "

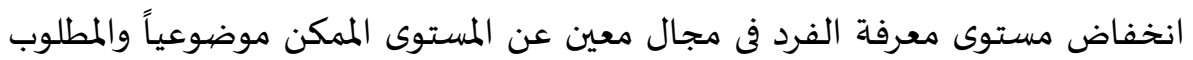

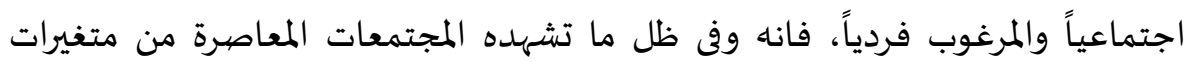

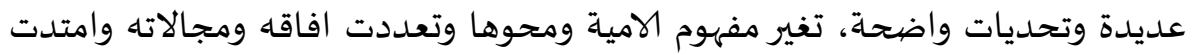

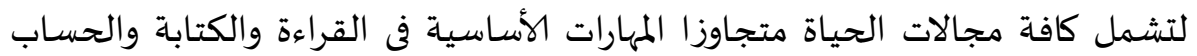

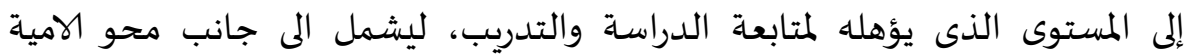

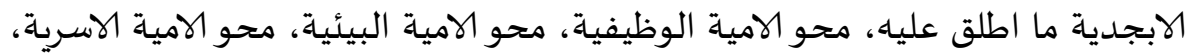
محو الامية الصحة، محو الامية الوجدانية، محو الامية المعلوماتية، محوالمية الدوائية، محو الامية القانونية .. وغيرها.

فالأمية مشكلة تحول بين الإنسان والحياة، وتجعله لا يبرح مكانه تفكيراً وتغييراً

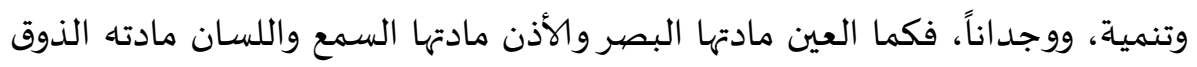
فكذلك العقل مادته الوعي والتنور.Literacy 
يعد التثقيف الدوائي من القضايا الهامة في مجتمعنا والذي يرفع من المستوى

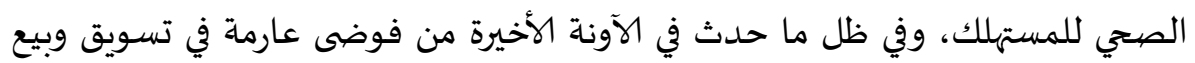

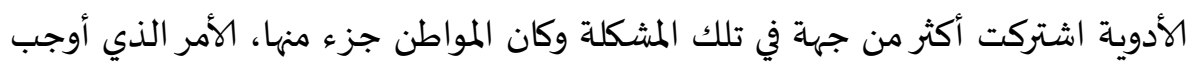

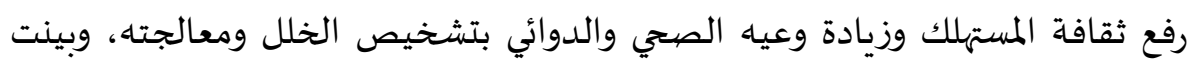

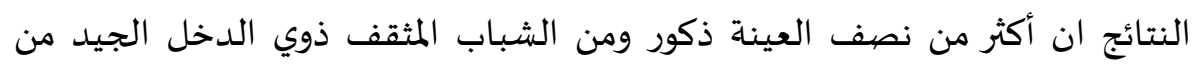

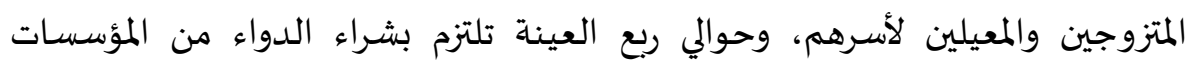
الصحية الحكومية وأكثر من نصف العينة تتجه إلى الصيدليات الأهلية وهنالك نسبة وهية قليلة تأخذ الدواء من باعة الرٔريفة. اننا في ظل تلك الظواهر السلبية المترتبة على العشوائية في استخدام الدواء الدواء في

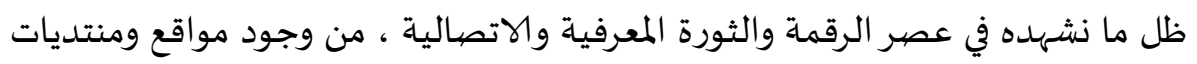

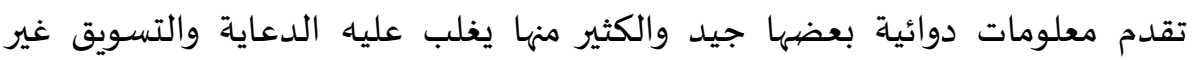

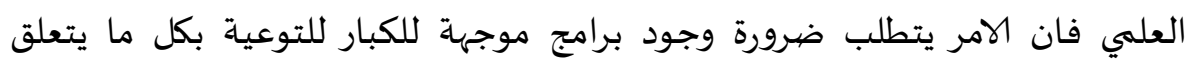

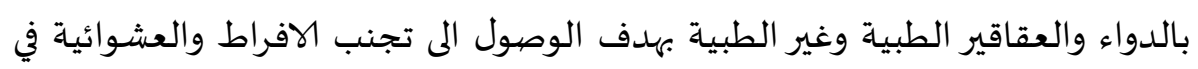

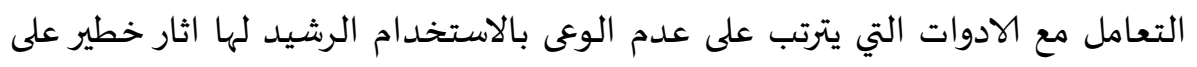

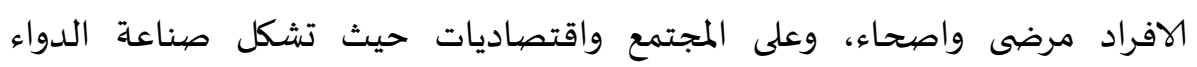

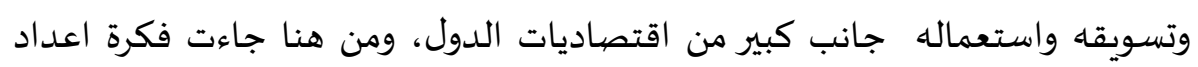

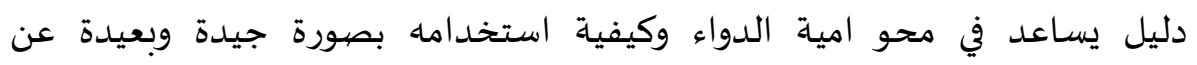
العشوائية . داعل فيساع.

فالثقافة الدوائية هي مجموعة المعارف والسلوكيات والاتجاهات المتعلقة بالاستخدام الصحيح للدواء والتداوي وتصحيح العادات السلبية للمداواة الذاتية وتخزين الدواء وملاحظة تاريخ إنتاجه والاعراض الجانبية الناتجاة عن استعماله والتقيد

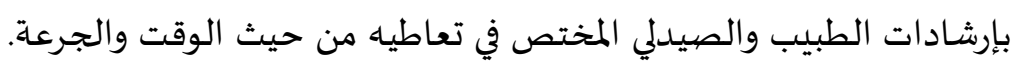


يعد محو الأمية الدوائية بعدًا من ابعاد ومحور محاور محو الأمية الصحية، نظرًا للدور الذي تلعبه الأدويـة في إدارة والتعامل مع الامراض، وتجنب حدوث إحداث اضرار ومخاطر نتيجة سوء استخدامها ،بالشكل الذى يؤدى الى الصحةة، ومن ثم كناوسنظل في هناك حاجة متزايدة لتعريف دقيق لمحو الأمية الصحية في سياق استخدام الأدوية، فالتنور الدوائي يقصد بـ "معرفة الأدوية هي الدرجة التي يمكن للأفراد من خلالها الحصول على المعلومات الخاصة بالمريض حول أدويتهم وفهمها والتواصل معها وحسابها ومعالجتها لاتخاذ قرارات مستنيرة بشأن الأدوية والصحية من أجل استخدام أدويتهم بأمان وفعالية، بغض النظر عن الوضع الذي يتم من خلاله يتم تسليم المحتوى (على سبيل المثال كتابيًا وشفهيًا ومرئيًا).

وفى ضوء ذلك يمكن تعريف التربية الدوائية على انها احد أنماط ومجال من مجال التربية الصحية المرتبطة بالدواء وكيفية استخدامه، اذا كانت التربية بصفة عامة تعنى مجموعة الجهود والأنشطة التي تتم لتنمية الأفراد تنمية شاملة متكاملة متوازنة لجميع جوانب شخصياتهم، لتجعل منهم أعضاء إيجابيين قادرين على تطوير أنفسهم ومجتمعهم ويتم عن طريقها تنمية جوانب الشخصية الانسانية في مستوياتها المختلفة، تلك المستويات التي شـاع بين المتخصصين أنها ثلاثة مستويات هي مستوى الوعي والادراك المعرفي، ومستوى العاطفة والوجدان ومستوى الحركة والنروع والمهارة، فان التربية الدوائية يقصيد بها مجموعة الجهود والأنشطة التي تتم لتنمية معارف وقيم

${ }^{4}$ Medication literacy is a large dimension of Health Literacy given the role medications play in disease management, and the potential for drug-related adverse events. There has been a growing need for a precise definition of health literacy in the context of medication use.

"Medication literacy is the degree to which individuals can obtain, comprehend, communicate, calculate and process patient-specific information about their medications to make informed medication and health decisions in order to safely and effectively use their medications, regardless of the mode by which the content is delivered (e.g. written, oral and visual).” 
ومهارات افراد المجتمع حول كيفية التعامل مع الدواء بصورة تجعله بحقق الهدف من استخدامه وينجنب هؤلاء الافراد المخاطر المى يمكن ان تترتب على العشوائية في استخدامه.

والواقع انه ليس المقصيود بالمعلومات التي نتناولها من هذا النوع من التربية الواردة من

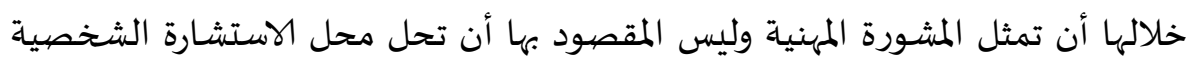

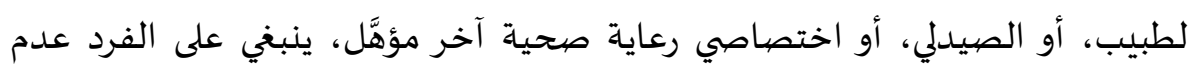

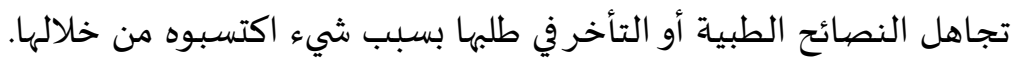

اما فيما يتعلق بأهداف التربية الدوائية والياتها لمواجهة عشوائية استخدام الدواء في مصر:

فانه في ضوء كل ما سبق تتحدد اهداف التربية الدوائية فيما يلي:

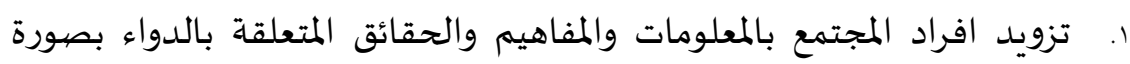
وظيفية تسهم في مساعدتهم على مواجهة مشكلاتهم الحياتية والصحية والمتعلقة بالدواء. r. تنمية الوعي الصحي والثقافة الصحية المتعلقة بالدواء وما يطلق عليه محو المواء الامية الدوائية او التنور الدوائي.

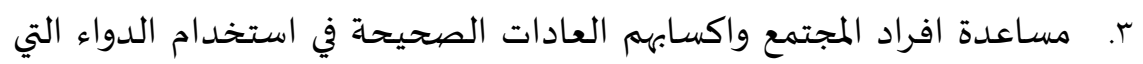
تساعد هم على السلوك الصيح السليم في مجال الاستخدام الرشيد للدواء

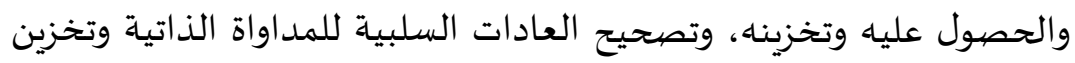

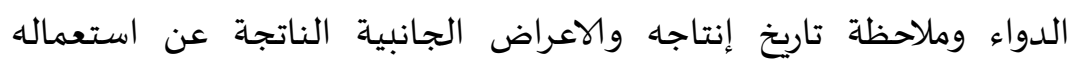

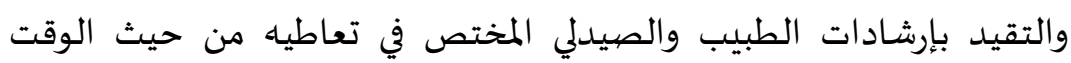
والجرعة. إكساب افراد المهارات الصحيحة اللازمة للتعامل الرشيد للدواء، مثل المهارات

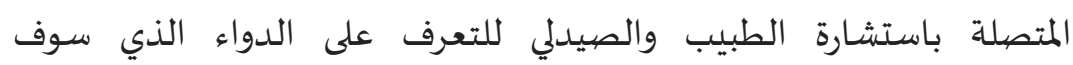

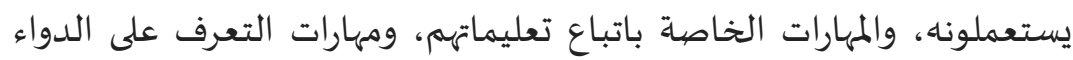
المغشوش والدواء منتهى الصلاحية ومهارات التخلص منها بطريقة امنة. 
تكوين الاتجاهات الصحية الايجابية عن الدواء ودوره في تحقيق الشفاء لدى الدي

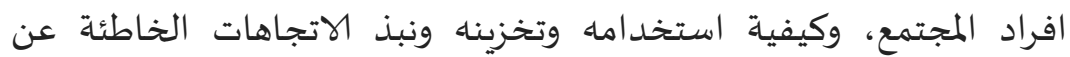
الحصول على الدواء ومصيادره الحصول عليه وأساليب تخزينه.

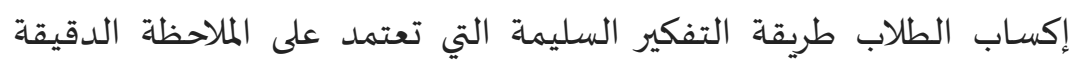
وتقبل الآراء والأحكام ذات الدليل الصحيح، وتحرير أفكارهم من المعتقدات التي لها تأثير سيء في سلوكهم وصحتهم. رابعا:التوصيات والمقترحات لتفعيل دور التربية الدوائية في مواجية فيتهائ الاستخدام العشوائي للدواء في مصر.

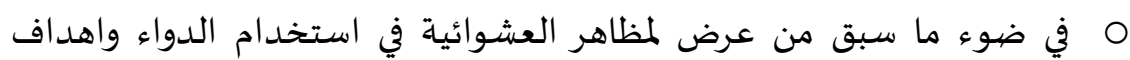
التربية الدوائية تعزيز دور وسائل الاعلام (بمختلف انواعها) واستخدام الوسائل المثلى لتفادي

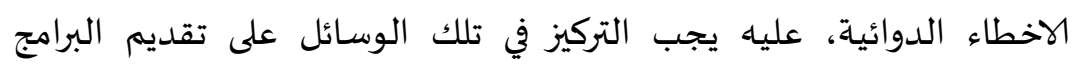

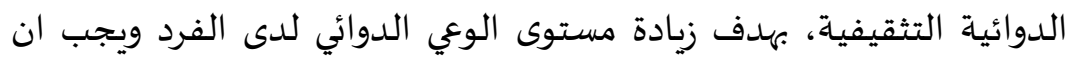

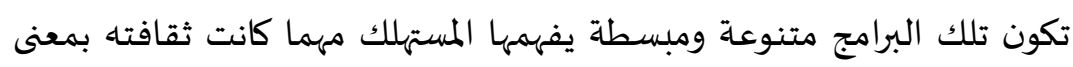
تلامس وتؤثر في شريحة واسعة في المجتمع.

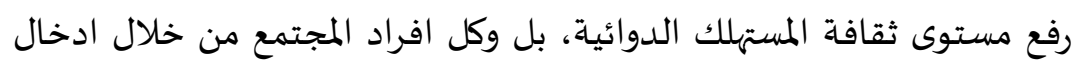

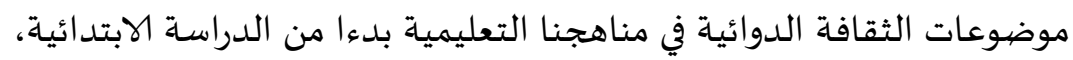

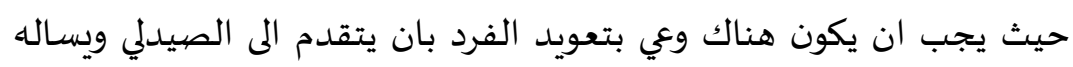

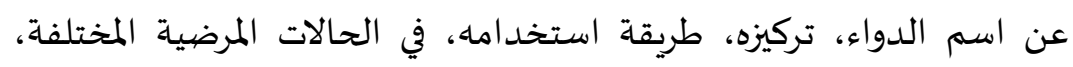

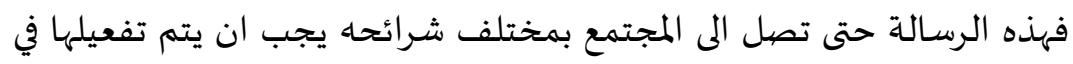

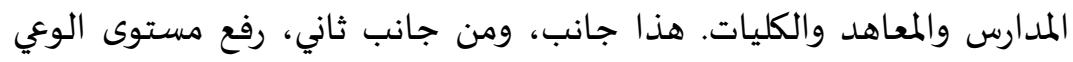

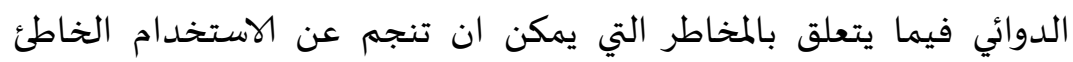

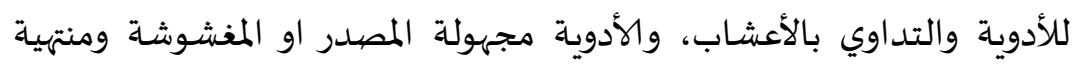
الصاحية.

تشكيل لجان مراقبة وتفتيش من وزارة الصحة للقيام بحملات على محلات

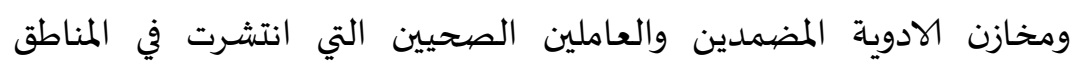


السكنية بشكل كبير (نتيجة الوضع الامني الصعب) وتشكيل لجان محلية تضم

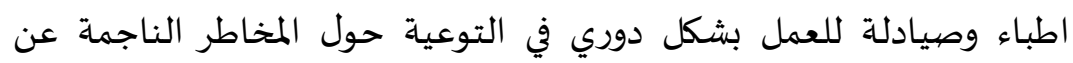

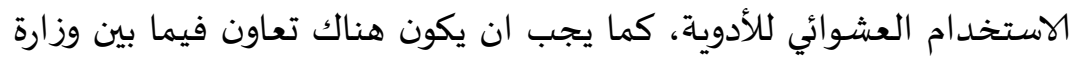

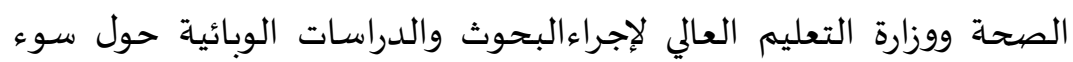

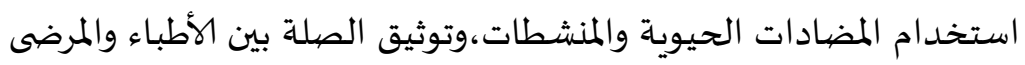

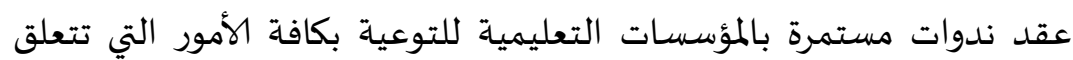
بالدواء واهميته، وواهميه وضرورة استخدامه بطريقة رشيدة، يدعى الهيها

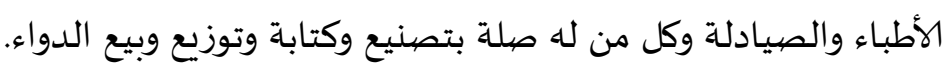

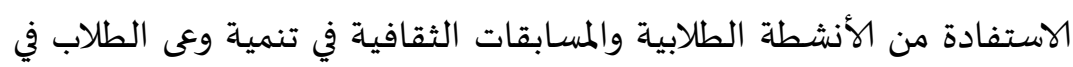

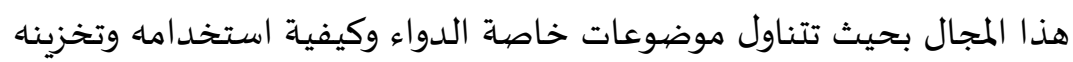
وكيفية تجنب اثاره الجانبية، والاستفادة منها في تحقيق الغاية من تناوله.

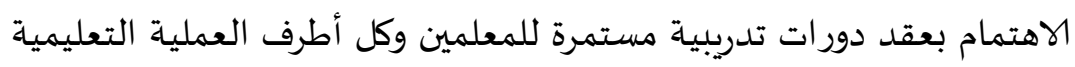

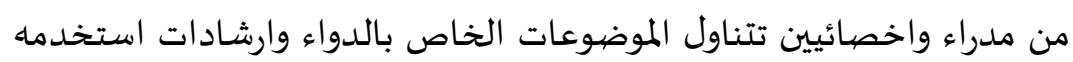

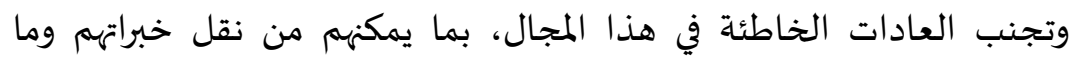
تعلموه اثناء هذه الدورات لطلابهم. التنسيق والتعاون فيما بين وزارة الصحة ووزارة الداخلية لاستحداث جهاز

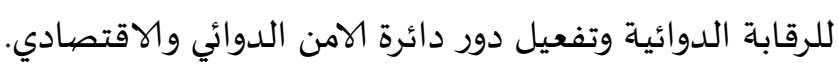

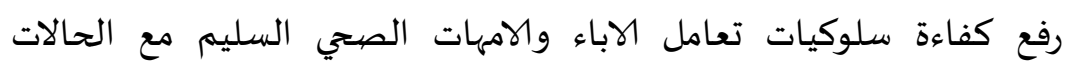
المرضية التي يتعرض لها اطفالهم، وهذا بطبيعة الحال يقتضي نشر الثقافة الأهات الدوائية من خلال الوسائل الاعلامية. من الضروري توفر صيدلية في المنزل تحتوي على مواد تحتوي على مواد واجهزة

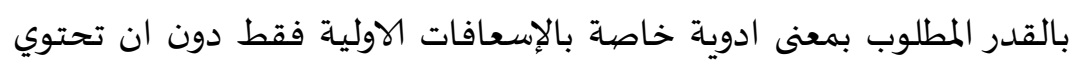

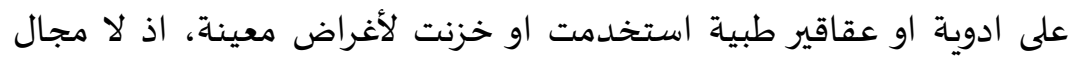

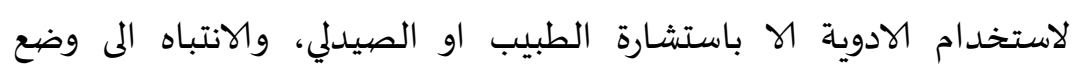
صيدلية المنزل في المكان المناسب وبعيدا عن متناول الاطفال. 
تفعيل دور الصيادلة في تثقيف المرضى وتوعيتهم بجميع الجوانب المتعلقة

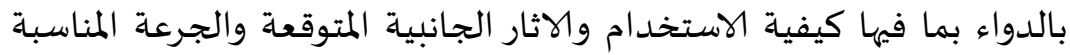

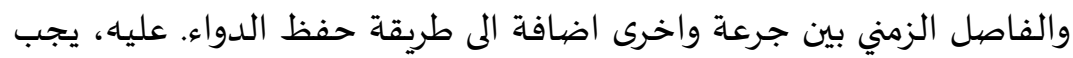

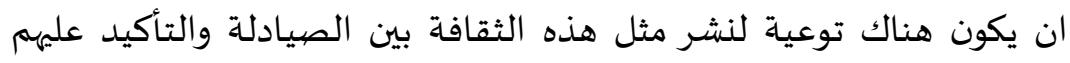
بتوعية المريض لرفع مستوى الثقافة الدوائية في المجتمع. تصحيح بعض السلوكيات غير المقبولة والمتعلقة بالمداواة الذاتية وتخزين الادوية في المنازل، التداوي بالأعشاب والوصفي لعات الشعبية. ترسيخ مفهوم الاستخدام الرشيد للدواء لدى افراد المجتمع من خلال الاجهزة

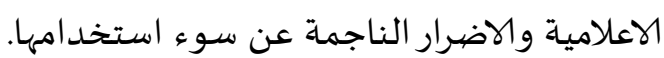
توعية افراد المجتمع بالطرق والأساليب الصحيحة لحفظ الادوية بطريقة

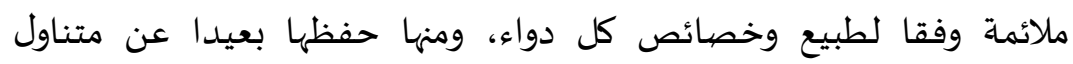

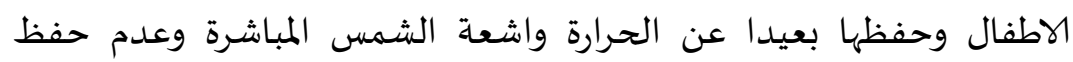

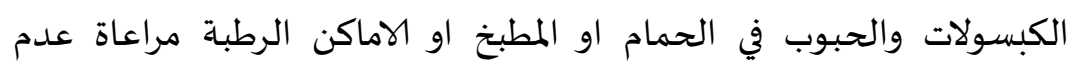

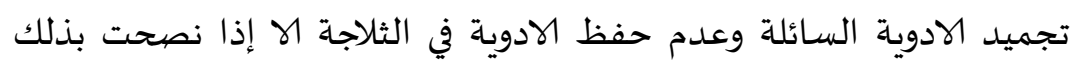

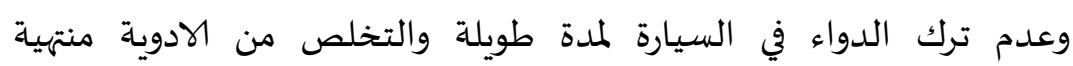

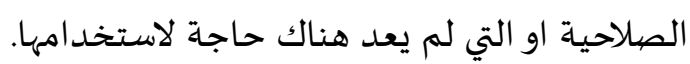
من الضروري ان تكون هناك جهة علمية محايدة متخصصية تقوم بتحليل

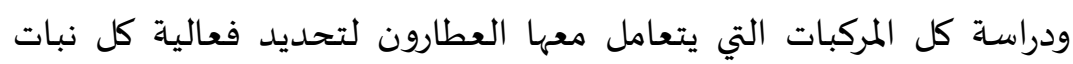
وتحديد نسب استخدامه وان تقوم شركات بتصنيع عبوات حديثة يمكن المركات للمستهلك التعامل معها بسهولة، مع الحرص الدائم على توافر المعلومات العلمية. قيام دور العبادة متمثلة في المساجد والكنائس والاديرة بدورها التربوي بجانب دورها الديني للتوعية بطبيعة الدواء وضرورة ترشيد استخدامدامها

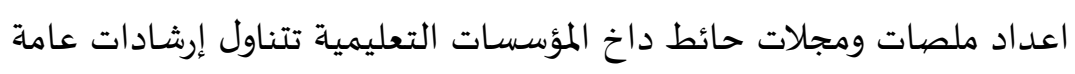
عن استخدام الدواء وتتمثل تلك الرشادات فيما يلي: 
افحص اسم الدواء الذي تتناوله. افحص أوقات اخذ الدواء وهل من الحاجة اخذ الدواء مع الطعام وهل من مانع لشرب الكحول معهـ. استفسر عن وظيفة الدواء المسجل لك. ماعك لكوبه اسأل الصيدلاني عن الاسم العلهي للدواء لان للدواء نفسه أسماء تجاريه مختلفة اقرأ اسم الدواء وجرعته قبل أن تتناوله.

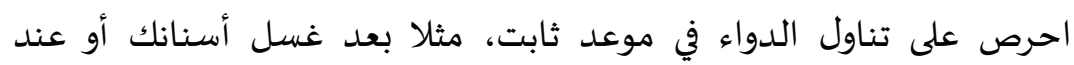
الاستيقاظ في الصباح أو بحسب تعليمات الطبيب أو الصيدلاني.

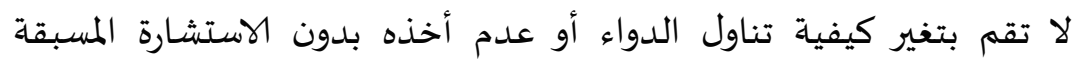
لطبيبك وإعلامه إن حدث أي تغير. احرص على اخذ الجرعة المسجلة لك. لا تأخذ وجبه اضافيه (مثلا إذا نسيت) اقل مما سجل لك.

قم بأخذ وجبه الدواء بالضبط كما سجل لديك فان تناول جرعه أكبر أو أصغر

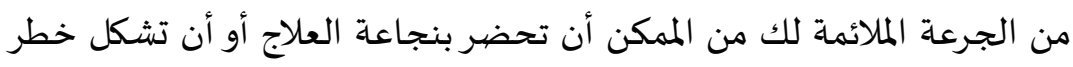
على صحتك. عليك بإبلاغ الطبيب أو الصيدلاني عن تناولك أدويه أخرى أو مكملات غذائية أو أدويه طبيعية. استفسر عن الأعراض الجانبية لدوائك. احرص على عدم تخزين الأدوية،ويتوجب عليك رمي الأدوية التي لست بحاجة المانة

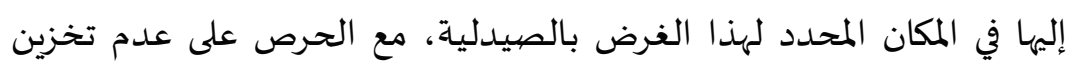

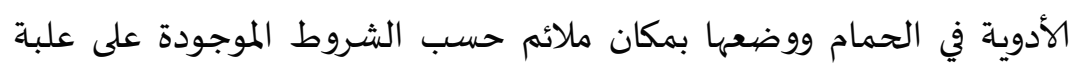
الدواء،وإبعاد الأدوية عن متناول أيدي الأطفال.

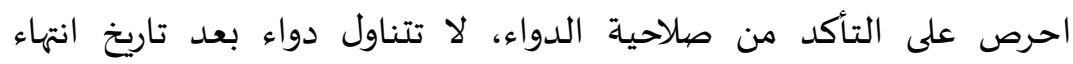

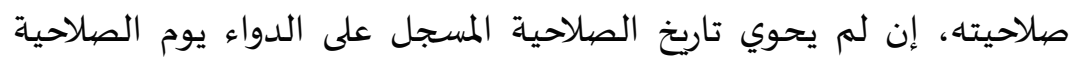

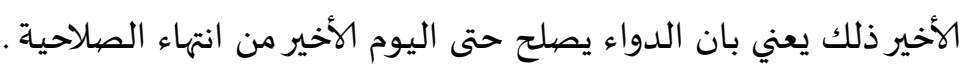


اذا نسيت تناول دواءك اسأل الصيدلاني عن طرق تسهل عليك أن تتذكر

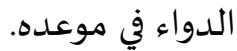

تذكر/ي تناول الأدوية بصوره منتظمة تساعد على نجاح ونجاعة العلاج الطبي. اشتري أدويه من صيدليه مرخصة فقط، إذا كنت غير متأكد قم بإبلاغ وزارة

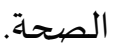

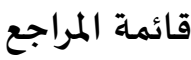

ابراهيم كاظم فرعون: التربية الصحية والبيئية- مطبعة الرائد النجف

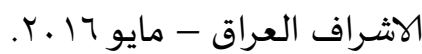
أحمد برقاوي : لا إحصاءات تبين حجم مشكلة الاستعمال غير الرشيد للدواء البـاء http://assabeel.net/news/2015/6/19/\%d9\%84\%d8\%a7-

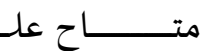
\%d8\%a5\%d8\%ad\%d8\%b5\%d8\%a7\%d8\%a1\%d8\%a7\%d8\%aa

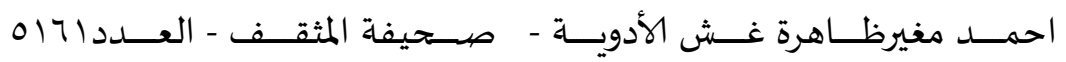
حا حل

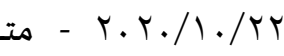
http://www.almothaqaf.com/a/b7/928852 أحمد مكاوي : الآثار الجانبية للأدوية : كيف تتجنب آثار الدواء الجانبية ؟متاح

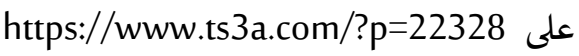
ادلة الارشـادية للمعرفة الطبية: سُمَّيَّة الجرعة الزائدة- متاح على https://www.msdmanuals.com/ar/home/\%D8\%A7\%D9\%84\%D8\%A3\%D8\%AF\%D9\%8 8\%D9\%8A\%D8\%A9/\%D8\%A7\%D9\%84\%D8\%AA\%D8\%A3\%D8\%AB\%D9\%8A\% D8\%B1\%D8\%A7\%D8\%AA\%D9\%8F الاستخدام المفرط للأدوية في الولايات المتحدة الامريكية، بيان الحقائق متاح 1.1935293https://www.albayan.ae/balsam/facts-figures/2013-08-03-على أمنية حسين: ماذا سيحدث لو تناولت دواءً منتهي الصلاحية؟ متاح على https://www.ida2at.com/what-would-happen-if-i-took-an-expired-medication/

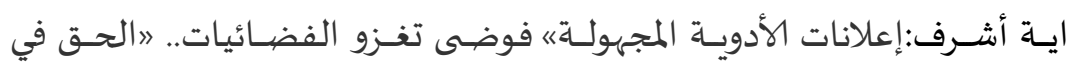

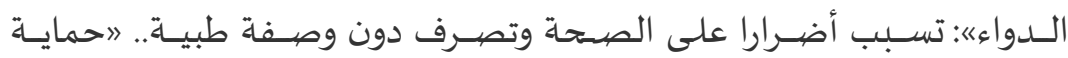

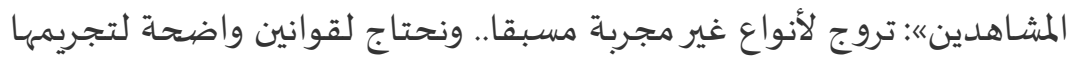


ح

http://www.soutalomma.com/Article/432591/\%C2\%AB\%D8\%A5\%D8\%B

9\%D9\%84\%D8\%A7\%D9\%86\%D8\%A7\%D8\%AA-

\%D8\%A7\%D9\%84\%D8\%A3\%D8\%AF\%D9\%88\%D9\%8A\%D8\%A9

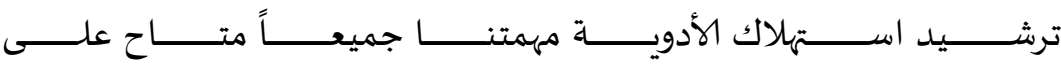
http://www.albayan.ae/balsam/pharmacy/2013-10-10-1.1976844 Pharmaceutical جمال على الدهشان: محو الامية الدوائية(التنور الدوائي) ضiteracy https://sadaalmokhtar.com/2019/11/21/\%d9\%85\%d8\%ad\%d9\%88\%d8\%a7\%d9\%84\%d8\%a7\%d9\%85\%d9\%8a\%d8\%a9جمال على الدهشان: محو الأمية الدوائية (التنور الدوائي) ضرورة للقضاء على فوضى استخدام الدواء في المجتمعات العربية متاح على https://elshare3news.com/2018/02/02/\%d9\%85\%d8\%ad\%d9\%88جمال على الدهشان واخرون: دليل محو الأمية الدوائية - مركز تعليم الكبار -

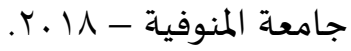

با. جمال على الدهشـان: محو الامية المعلوماتية الدوائية Information Literacy السنـوي السـادس عشـر لمركز تعليم الكبار بجامعة عـن شمسـتعليم الكبار في

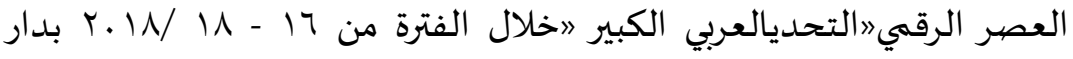
الضيافة بجامعة عين شمس. " جمال على الدهشان: نحو افاق جديدة لمحو الامية المجتمعية في المجتمعات

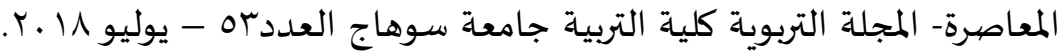
معرف الوثيقة الرقهي 10.12816/EDUSOHAG.2018.17175: حسن محمد صندقبجي: وصف الأدوية الخطأ.. خطأ طبي قاتل، متاح على https://altibbi.com/\%D9\%85\%D9\%82\%D8\%A7\%D9\%84\%D8\%A7\%

D8\%AA\%D8\%B7\%D8\%A8\%D9\%8A\%D8\%A9/\%D8\%B5\%D8\%AD\%D8\%

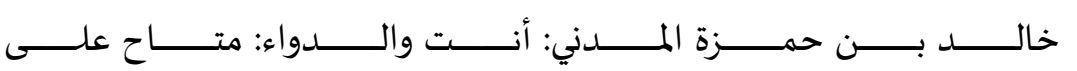
.17 https://www.tbeeb.net/ask/showthread.php?t=130469 


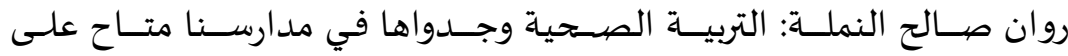
https://makkahnewspaper.com/article/1512361/\%D8\%AA\%D9\%81\%D8\% A7\%D8\%B9\%D9\%84/\%D8\%A7\%D9\%84\%D8\%AA\%D8\%B1\%D

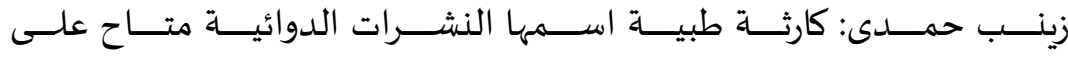
https://www.masress.com/rosaweekly/22696 سنن أبي داود" كتاب الطب" باب في الرجل يتداوى

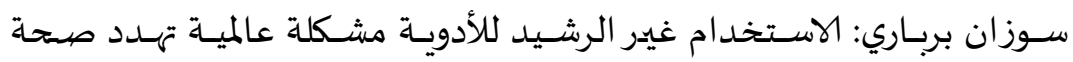

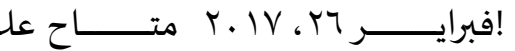

http://greenarea.me/ar/203984/\%d8\%a7\%d9\%84\%d8\%a7\%d8\%b3\%d8\%aa d8\%ba\%d9\%8a\%d8\%b1-\%d8\%ae\%d8\%af\%d8\%a7\%d9\%85-\% سـوزان زمزم: دور الإدارة المدرسية في تحقيق التربية الصحية المدرسية لطلاب مرحلـة التعلـيم الأسـاسـي في مدينـة اللاذقيـة- مجلـة جامعـة تشـرين للبحــوث

$$
\text { والدارسات العلمية - المجلد مب العدد ب م } 17 \text {.r. }
$$

صـالح محمـد صـالح: فعاليـة برنـامج مقترح في التربيـة الصصحية في تنميـة التنـور الصي لدى تلاميذ المرحلة الإعدادياة بشـمال سيناء - مجلة التربية العلميـة -

$$
\text { المجلد الخامس - العدد الرابع - r . . r. }
$$

عاطف سـالم حسن: فاعلية برنامج مقترح في الثقافة الصحية على تنمية الوعي الغـذائي والـوعي الـدوائي لـدى طالب كليـة التربيـة بالمملكـة العربيـة السـعودية،

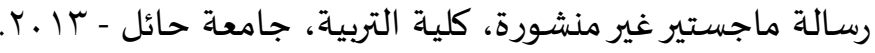

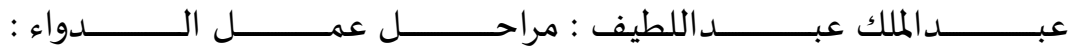
http://keefwiki.com/health/2015/03/31/\%D9\%83\%D9\%8A\%D9\%81\%D9\% 8A\%D8\%A9-\%D8\%B9\%D9\%85\%D9\%84-

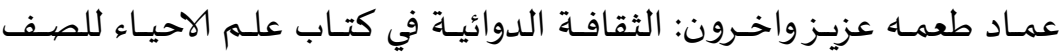
الثالث المتوسـط ومـدى تضهمين الطلاب لها في سـلوكهم - كليـة التربيـة جامعـة

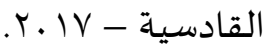
عمــاد عبــ الحميـد، مرفت عبــد الحميـد: النشـرة الدوائيـة، خريطـة طريـق

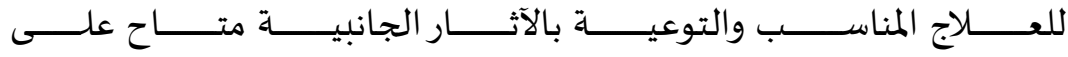
https://www.albayan.ae/health/features/2016-12-25-1.2805704 عمـاد عيسـى، أمـاني السـيد. دور المكتبـات العامـة في تنميــة الـوعي الصــي rV ومكافحـة الأزمات الصصحية العالميـة: دراسـة استكشـافية مقارنـة لبرامج وأنشطة 
المكتبات في ضوء وباء الأنفلونزا. .في: المؤتمر العشرون للاتحاد العربي للمكتبات والمعلومات تحت عنوان "نحو جيل جديد من نظم المعلومات والمتخصصيسين:

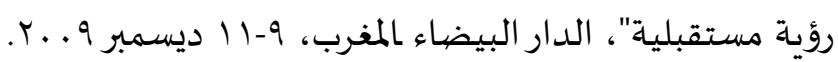

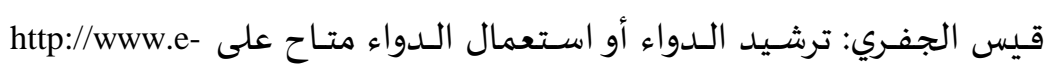
moh.com/vb/t106608/

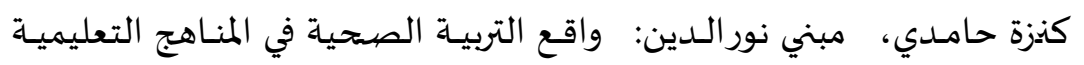

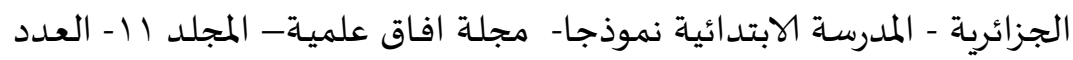
r. 19 -

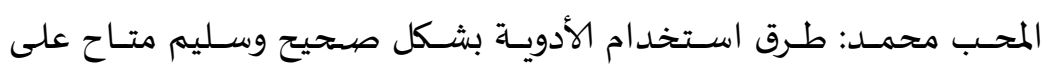

http://www.ce4arab.com/vb7/showthread.php?t=219447

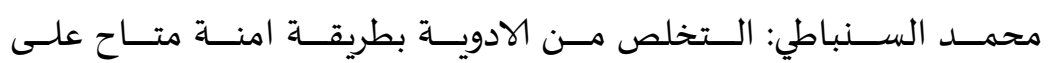
https://www.sehatok.com/info/2017/10/24/\%D8\%A7\%D9\%84\%D8\%AA\% D8\%AE\%D9\%84\%D8\%B5-\%D9\%85\%D9\%86محمد العواجى، سـامية العيسى: 35\% من الأدوية المتداولة في الصيدليدليات.

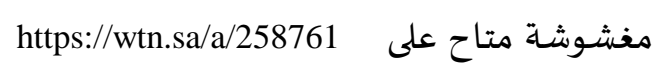
محمد معوض عبدالهادي فايد: دور التعليم الثانوي في تنميـة الوعي الدوائي مغئي

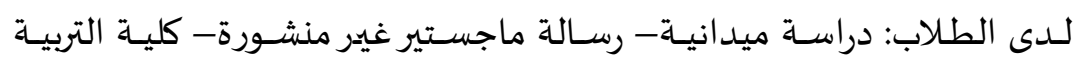

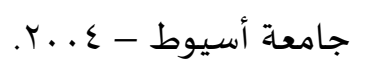

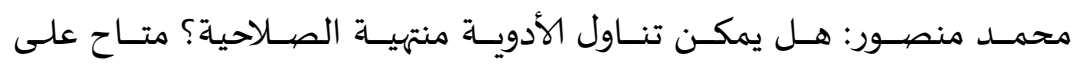
https://www.alroeya.com/172-68/2061951-\%D9\%87\%D9\%84

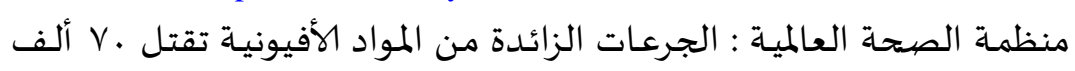

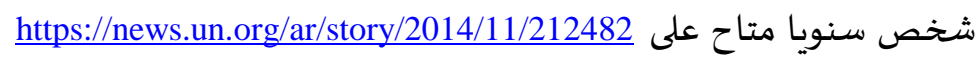

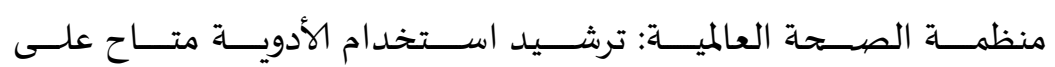
https://www.who.int/medicines/areas/rational_use/ar/

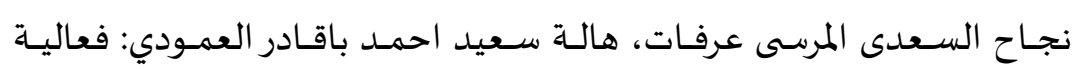
rv

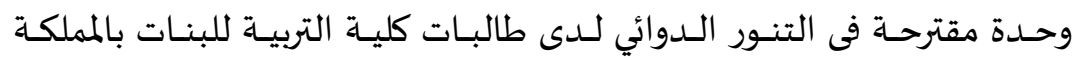

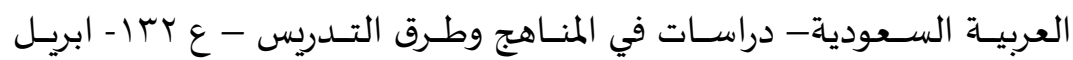

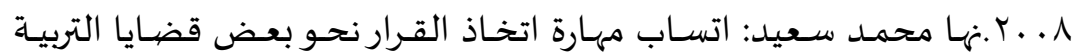




$$
\begin{aligned}
& \text { الحياتية من خلال التعامل مع العقاقير - رسالة ماجستير غير منشورة - كلية } \\
& \text { التربية - جامعة القاهرة فرع الفيوم - جامعة القاهرة - } 1990 .
\end{aligned}
$$

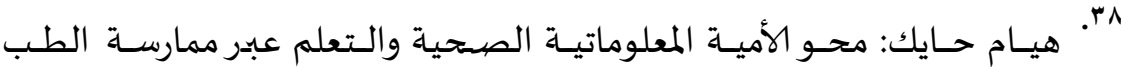

: : Evidence-based medicine متاح على

http://www.ncbi.nlm.nih.gov/pmc/articles/PMC3016648/

9". الهيئة العامة للغذاء والدواء بالمملكة العربية السعودياة: المؤتمر الإقليمي الثاني

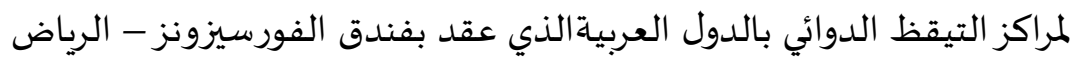

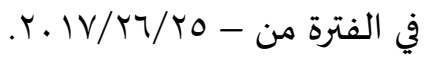

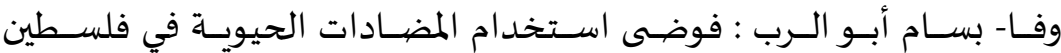
عاح

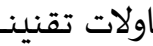
ومح

http://www.wafa.ps/ar_page.aspx?id=bR0U7ja749803386189abR0U7j

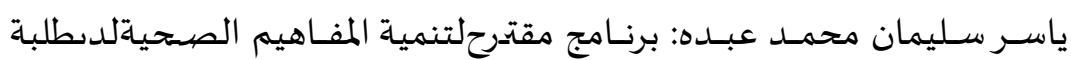
الصف السادس بمحافظات غزة - رسالة ماجستير - كلية التربية- الجامعـة

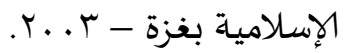

42. Brach, C. A guide for developing and purchasing successful health information technology. Power-point presentation at the Institute of Medicine (IOM) workshop on health literacy, e-Health, and communication: Putting the consumer first. Washington, DC, March 17. CDC (Centers for Disease Control and Prevention). 2008. Prevention research centers. http://www.cdc.gov/prc/ Accessed May 14, 2010

43. Daphne E. Smith Marsh, Overdose Toxicity,College of Pharmacy, University of Illinois at Chicago Last full review/revision Sep 2018 Content last modified Sep 2018,https://www.who.int/medicines/areas/rational_use/ar/

44. McKinney J, Kurtz-Rossi S. Culture, Health, and Literacy: A Guide to Health Education Materials for Adults With Limited English Skills. Boston, MA: World Education; 2000

45. Shalini S. Lynch, Drug Interactions,University of California San Francisco School of Pharmacy Last full review/revision Aug 2019| Content last modified Aug 2019, https://www.msdmanuals.com/home/drugs/factors-affectingresponse-to-drugs/drug-interactions 
46. U.S. FOOD\&DRUG ADMENISTRATION: Administration Disposal of Unused Medicines: What You Should, learn how to dispose of unused or expired drugs, Disposal of Unused Medicines: What You Should Know Learn how to dispose of unused or expired drugs. 